\title{
On Joint State Estimation and Model Learning using Gaussian Process Approximations
}

\section{Anton Kullberg}



Linköping studies in science and technology. Licentiate Thesis

No. 1917

\section{On Joint State Estimation and Model Learning using Gaussian Process Approximations}

Anton Kullberg

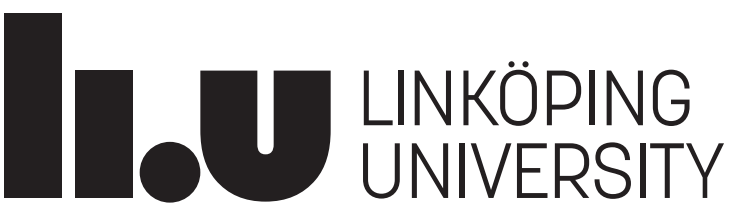


This is a Swedish Licentiate's Thesis.

Swedish postgraduate education leads to a Doctor's degree and/or a Licentiate's degree.

A Doctor's Degree comprises 240 ECTS credits (4 years of full-time studies).

A Licentiate's degree comprises 120 ECTS credits,

of which at least 60 ECTS credits constitute a Licentiate's thesis.

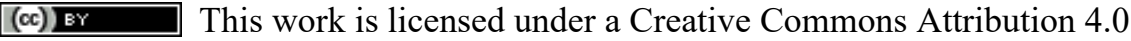
International License.

https://creativecommons.org/licenses/by/4.0

Linköping studies in science and technology. Licentiate Thesis

No. 1917

On Joint State Estimation and Model Learning using Gaussian Process Approximations

Anton Kullberg

anton.kullbergeliu.se

ww. control.isy.liu.se

Department of Electrical Engineering

Linköping University

SE-581 83 Linköping

Sweden

ISBN 978-91-7929-141-9 (Print)

ISSN 0280-7971

ISBN 978-91-7929-142-6 (PDF)

Copyright (C) 2021 Anton Kullberg

Printed by LiU-Tryck, Linköping, Sweden 2021 
To family and friends! 



\section{Abstract}

Techniques for state estimation is a cornerstone of essentially every sector of science and engineering, ranging from aeronautics and automotive engineering to economics and medical science. Common to state estimation methods, is the specification of a mathematical model of the underlying system in question. Typically, this is done a priori, i.e., the mathematical model is derived based on known physical relationships and any unknown parameters of the model are estimated from experimental data, before the process of state estimation is even started.

Another approach is to jointly estimate any unknown model parameters together with the states, i.e., while estimating the state of the system, the parameters of the model are also estimated (learned). This can be done either offline or it can be done online, i.e., the parameters are learned after the state estimation procedure is "deployed" in practice. A challenge with online parameter estimation, is that it complicates the estimation procedures and typically increases the computational burden, which limits the applicability of such methods to models with only a handful of parameters.

This thesis aims to investigate how online joint state estimation and parameter learning can be done using a class of models that is physically interpretable, yet flexible enough to be able to model complex dynamics. Particularly, it is of interest to construct an estimation procedure that is applicable to problems of a large scale, which is challenging due to a high computational burden because the models typically need to contain many parameters. Further, the ability to detect sudden deviations in the behavior of the observed system with respect to the learned model is investigated.

The studied model class consists of an a priori specified part providing a coarse description of the dynamics of the considered system and a generic model part that describes any dynamics that is unknown a priori and is to be learnt from data online. In particular, a subclass of these models, in which it is assumed that the spatial correlation of the underlying process is limited, is studied. A computationally efficient method to perform joint state estimation and parameter learning using this model class is proposed. In fact, the proposed method turns out to be nearly computationally invariant to the number of model parameters, enabling online inference in models with a large number of parameters, in the order of tens of thousands or more, while retaining the interpretability. Lastly, the method is applied to the problem of learning motion patterns in ship traffic in a harbor area. The method is shown to accurately capture vessel behavior going in and out of port. Further, a method to detect whether the vessels are behaving as expected, or anomalously, is developed. After initially learning the vessel behaviors from historical data, the anomaly detection method is shown to be able to detect artificially injected anomalies. 



\section{Populärvetenskaplig sammanfattning}

Modeller är oumbärliga för hur vi människor förstår världen omkring oss. Inom vetenskapen så är dessa modeller framförallt matematiska och har historiskt sett baserats på vår förståelse av fysikaliska fenomen. Således krävs det lång tid och mycket resurser för att dessa modeller skall bli mer avancerade och kunna förklara mer komplexa fenomen. Trots detta, har dessa så kallade vitlådemodeller lett till många fantastiska tekniska uppfinningar, framförallt ledande upp till den digitala eran.

Inne i den digitala eran, så har de matematiska modellerna vi använder oss av blivit mer och mer abstrakta och komplexa, med tusentals eller miljontals parametrar. Dessa parametrar saknar ofta en fysikalisk tolkning, vilket är vitalt för vår förståelse för hur dessa modeller fungerar. Därav kallas dessa modeller ofta för svartlådemodeller, i kontrast till vitlådemodellerna som helt och hållet går att fysikaliskt tolka. Mellan dessa två typer finns grålådemodeller, som är en slags kombination av en fysikaliskt tolkningsbar modell som beskriver det vi redan känner till om ett specifikt system och en generell abstrakt struktur som beskriver de egenskaper vi inte känner till. En sådan modell har både egenskapen att den kan beskriva komplexa fenomen samt att den är fysikaliskt tolkningsbar.

Vad är då nyttan med dessa modeller? Varför skall vi ha dem och vad skall vi ha dem till? Modeller lägger grunden till hur vi beskriver så kallade system. Ett system kan antingen vara någonting fysiskt, så som en bil, en byggnad eller en kaffekokare. Det kan också vara något icke fysiskt, så som aktiemarknaden eller ett tv-spel. Gemensamt för dessa ting är att vi är intresserade av systemets tillstånd. Ett tillstånd kan t.ex. vara hastigheten eller totala lasten på en båt, temperaturen eller antalet personer i en byggnad eller priset och volatiliteten hos en aktie. I nästintill samtliga vetenskapliga grenar så är en noggrann skattning av dessa tillstånd av stort intresse, för att t.ex. kunna planera rörelsen hos ett självkörande fordon, med säkerhet kunna välja vilken aktie man skall investera i, kunna sänka energiförbrukningen för ventilationssystem med mera. För att skatta ett tillstånd så krävs någon typ av modell och beroende på hur väl denna modell beskriver systemet i fråga, så kommer tillstånden att kunna skattas mer eller mindre bra.

En naturlig fråga att ställa sig då är hur vi får tillgång till bättre modeller? Bättre modeller får vi antingen genom att mer matematiskt noggrannt beskriva systemet vi är intresserade av genom de fysikaliska samband som råder, eller så genomför vi experiment och försöker att lära oss en modell. Så kallade lärande system är ingenting nytt, men har funnit mer och mer praktisk användarbarhet över tid. Framförallt är det vår beräkningskraft som har blivit bättre och bättre med tiden, vilket låtit oss använda mer och mer avancerade lärande system, även i t.ex. våra mobiltelefoner. Det finns dock fortfarande en tröskel för de mest komplexa modellerna, som fortfarande är alltför beräkningsmässigt tunga, men som vi vill nyttja för att förbättra dels tillståndsskattningen, men även vår förståelse för det system vi försöker modellera.

Den här licentiatavhandlingen tar en närmre titt på en typ av modell som är både fysikaliskt tolkningsbar samt avancerad nog att beskriva komplexa feno- 
men. Framförallt ligger intresset här i att modellera och förstå storskaliga system som kräver modeller med tiotusentals parametrar eller fler. T.ex. skulle en sådan modell kunna beskriva hur bilförare beter sig i olika trafikscenarier, hur meteorologiska fenomen utvecklas över tid, hur personer tenderar att röra sig i en stad med mera. Dessa modeller kan sedan nyttjas för att t.ex. underlätta rörelseplanering för självkörande fordon, utgöra beslutsstöd för katastrofhjälp eller minska energiförbrukningen i våra mobiltelefoner genom smartare uppkopplingar till mobilnäten.

I denna licentiatavhandlingen beskrivs först modellen, inlärningen och en vanlig tillståndsskattningsprocedur i ett generellt sammanhang och det påvisas att tillståndsskattningen blir klart bättre. Sedan modifieras både modellen, inlärningen och tillståndsskattningen sådant att inlärning och tillståndsskattning kan ske i realtid, även för en modell med tiotusentals parametrar. 


\section{Acknowledgments}

First of all, I would like to thank my supervisor Assoc. Prof. Gustaf Hendeby, and co-supervisor Assoc. Prof. Isaac Skog. You have provided me with exceptional support and technical insight into any and all problems I have faced. Your ideas, both research related and career wise, are invaluable to me. Also, a particular thank you to Gustaf. Had you not called during the end of my master's thesis and pushed me to pursue a $\mathrm{PhD}$, I would not be here today. It turned out to be one of the best decisions of my life.

Thanks to Assoc. Prof. Martin Enqvist, head of division, partly for maintaining a friendly and open workplace, but also for your openness to new ideas. You have a unique ability to make people feel welcomed and heard, regardless of their background or position. Also, thanks to Ninna Stensgård for taking care of all practicalities.

All of my colleagues, former and present, at the Automatic Control division, thank you for the past two years. Thank you for the friendly environment, the discussions in the fika room and the occasional visit to the pub. I very much look forward to the rest of my time at the division. A special thank you to Tekn.Lic. Magnus Malmström for your comments on the manuscript.

This work was supported by the Wallenberg AI and Autonomous Systems and Software Program (WASP). Thank you partly for financing my pursuit of a PhD, but mainly for providing ample opportunity to network with a fantastic group of people. I hope to be able to make use of these opportunities even more in the coming years.

To my family, thank you for all of your love and support. Even though I am awful at keeping in touch, I am always happy to see you and hear from you.

To my second family (in alphabetical order!), Feri Bagherpour, Tobias Fridén, Julia Gloppestad, Karl Gudmundson, Johanna Kilander, Kajsa Krämer, Daniel Strannelind, Christopher Sundkvist, Caroline Wasing, Theodor Westny, and Lina Åberg. You are the best friends anyone could ask for. The fun times we have, have had, and will have, are extremely precious to me. The support and belief you've shown me has served as a fantastic motivation.

Lastly, thank you Lovisa. Thank you for putting up with my shenanigans and for your endless support during stressful times. You are my favorite person in the world. 



\section{Contents}

\section{Background}

1 Introduction 3

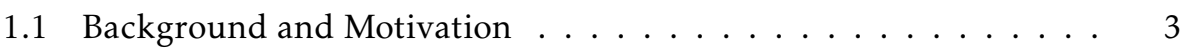

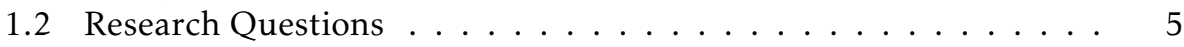

1.3 Publications and Contributions ................. 6

1.4 Thesis Outline . . . . . . . . . . . . . . 7

2 Function Approximation 9

2.1 Gaussian Processes ............................ 10

2.1.1 Computational Challenges . . . . . . . . . . . . 12

2.1 .2 Inducing Inputs . . . . . . . . . . . . . . . 12

2.2 Basis Function Expansion . . . . . . . . . . . . 15

3 Dynamical Systems and State Estimation 19

3.1 State-Space Models . . . . . . . . . . . . . . . . . . . 19

3.1.1 Discrete State-Space Models . . . . . . . . . . . 20

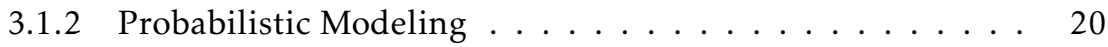

3.2 State Estimation . . . . . . . . . . . . . . 21

3.3 Parameter Estimation ................... 22

4 Joint State Estimation and Function Approximation 25

5 Concluding Remarks 29

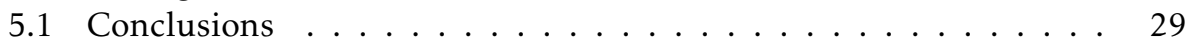

5.2 Future Work ......................... 30

$\begin{array}{ll}\text { Bibliography } & 31\end{array}$ 


\section{Publications}

A Learning Driver Behaviors Using A GPASSM 37

B Online Joint State Inference and Learning of PUSSM 45

C Learning Motion Patterns in AIS Data $\quad 59$ 
Notation

\section{Mathematical Notation}

\begin{tabular}{cl}
\hline Notation & Meaning \\
\hline $\mathbb{R}$ & Set of real numbers \\
$\mathbb{R}^{n}$ & Set of real $n$ vectors \\
$\mathbb{R}^{n \times n}$ & Set of real $n \times n$ matrices \\
$x$ & Scalar \\
$\mathbf{X}$ & Vector \\
$\mathbf{X}$ & Matrix \\
$\mathbb{E}[x]$ & Expected value of $x$ \\
$\sim$ & Distributed as \\
$\operatorname{cov}[\mathbf{x}]$ & Covariance of the elements of $\mathbf{x}$ \\
$\operatorname{diag}[X]$ & Diagonal of $X$ \\
\hline
\end{tabular}

\section{Abbreviations}

\begin{tabular}{cl}
\hline Abbreviation & Meaning \\
\hline AIS & Automatic Identification System \\
BF & Basis Function \\
EKF & Extended Kalman Filter \\
FIC & Fully Independent Conditional \\
GP & Gaussian Process \\
GPS & Global Positioning System \\
GPSSM & Gaussian Process State-Space Model \\
KF & Kalman Filter \\
RBF & Radial Basis Function \\
SSM & State-Space Model \\
\hline
\end{tabular}



Part I

Background 



\section{1}

Introduction

This introductory chapter puts this thesis into its context, provides a motivational background to the topic of interest, presents the outline of the thesis, and highlights the research contributions of the author.

\subsection{Background and Motivation}

Techniques for state estimation is a cornerstone of essentially every sector of science and engineering, ranging from aeronautics and automotive engineering to economics and medical science. Here, the interest lies with a specific type of state estimation, namely filtering. Filtering is the process of estimating the state of a system at a specific time $t$, given measurements from some time $t_{0}$ to time $t$. Common to state estimation methods, is the specification of a mathematical model of the system in question. Typically, and especially in the filtering setting, this is done a priori, i.e., the mathematical model is completely defined before the state estimation procedure is started. This is either done through physical modeling, where mathematically established relationships, such as Newton's laws of motion, are used to manually derive the system model, or the model is learned from data using system identification techniques [11].

A mathematical model of a system can be either gray-box, with physical interpretation, see e.g. [12], or it can be black-box, with limited or no physical interpretation, e.g., neural networks $[13,21]$. The interest in this thesis lies primarily with gray-box models and particularly with gray-box models that consist of a well established physical model augmented with a general black-box structure. The idea of this type of model construct is not new and different versions of it can, e.g., be found in $[6,23,28]$. The Gaussian Process State-Space Model (GPSSM) is one example of a model that can be interpreted in this sense, see $[2,6,23,24]$. This model is both flexible, as well as physically interpretable (in some cases). This 


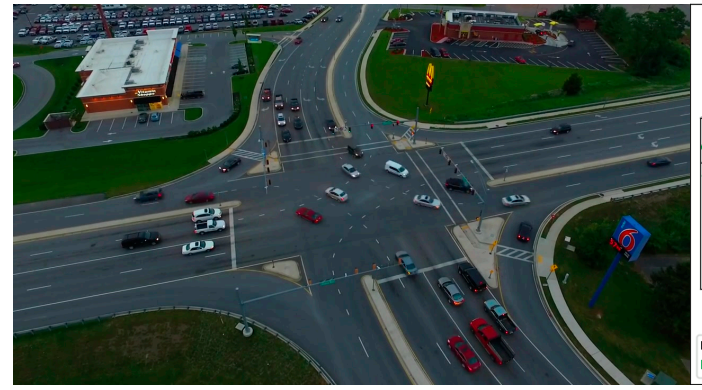

(a) A four-way intersection with semideterministic motion patterns. Image courtesy of Tyler Lindsay.

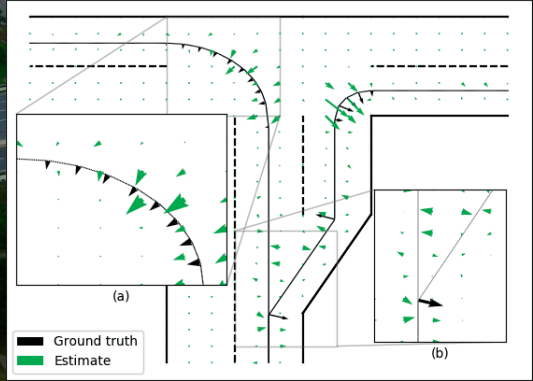

(b) Learned vehicle acceleration throughout a three-way intersection

Figure 1.1: An intersection scenario where vehicles adhere to specific traffic regulations and typically follow semi-deterministic motion patterns, see (a). Methods that can efficiently learn these patterns can enable more advanced motion planning techniques which takes these patterns into account. These motion patterns can for instance be captured by the vehicle acceleration throughout the intersection, such as in (b).

thesis concerns a particular type of GPSSM, which consists of an a priori specified State-Space Model (SSM), augmented with a Gaussian Process (GP), see e.g. [28]. This model is interpretable by construction and otherwise shares properties with other types of GPSSMs. The primary drawback with these models, in their standard formulation, is that they are computationally prohibitive. This thesis explores some remedies to this problem and focuses primarily on the challenge of online inference of large-scale models, where the number of parameters are in the order of tens of thousands or more.

Such large-scale models are useful for instance when trying to learn how pedestrians typically move in a city to efficiently predict how to switch mobile network base stations, or to provide indoor positioning through the use of magnetic field measurements [6]. In this thesis, mainly two problems requiring such large-scale models are explored, which serve as numerical examples of the types of problems that are of interest. The first problem focuses on a, to many, familiar setting of an intersection, pictured in Figure 1.1. In this scenario, vehicles (or drivers) adhere to specific traffic regulations and typically follow partially deterministic motion patterns, see Figure 1.1a. This information can for instance be captured by the vehicle acceleration throughout the intersection, such as in Figure 1.1b. Learning this information could potentially open up for more advanced decision making for autonomous vehicles, where predicted vehicle trajectories can be taken into account to optimize the trajectory of the own vehicle. Another possibility is to lower the measurement frequency of the onboard sensors, as the necessary state dynamics information is available purely through the learned motion patterns, potentially saving energy if used on a regular basis. 


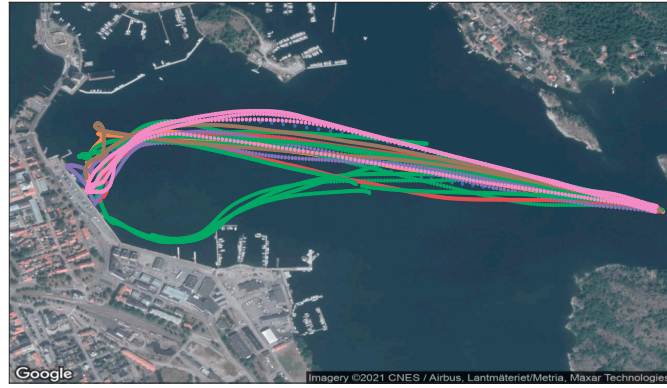

(a) Original GPS data. The dots in are GPS measurements from ships traveling in the region between January 2019 and April 2020. Data courtesy of the Swedish Defense Research Agency (FOI).

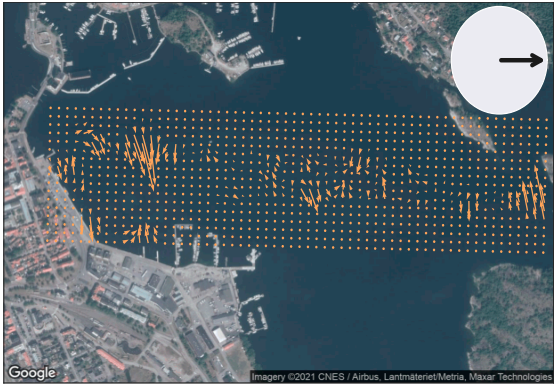

(b) Learned vessel acceleration going out of port. The top right arrow shows the direction of travel of the vessel.

Figure 1.2: A coastal region outside Västervik, Sweden, where ships travel in and out of port. It is apparent from (a) that the ships follow specific routes in and out of the harbor. Deviations from these routes or motion patterns could be indications of, e.g., illicit activity or an accident. By learning the motion dynamics of the vessels in this particular region, see (b), such activity can potentially be detected through the deviations from these learned dynamics.

The second problem primarily concerns detection of anomalous behavior, in the sense that the model is not able to adequately describe the behavior of the observed system. Particularly, the anomaly detection is exemplified through a maritime safety example, where a harbor area is to be surveilled, see Figure 1.2a. The ships traveling in the region adhere to specific routes when traveling in and out of the harbor area. Deviations from these routes may be an indication of, e.g., illicit activity or an accident. Detecting such deviations can for instance be done by learning the motion dynamics throughout the surveillance region, see Figure 1.2b. Further, it is in this context also possible to utilize the motion information to make informed decisions for motion planning, potentially increasing safety and efficiency moving throughout the harbor.

Thus, this thesis is concerned with efficient online learning of partially unknown, augmented state-space models, particularly aimed toward models where the number of parameters is in the order of tens of thousands or more.

\subsection{Research Questions}

This thesis aims to investigate a certain type of interpretable, but flexible, model class and how it can be utilized for problems of a large-scale. Specifically, the thesis aims to answer the following questions: 
- In what types of applications is it beneficial to combine an a priori known, physically established, model with a black-box structure to yield an interpretable, yet flexible model?

- How can such a model be made practically useful in a wider range of applications, particularly for problems that are of a large scale and require models with tens of thousands of parameters or more?

- How can it be detected whether a system is behaving as expected or anomalously and how should an anomaly be defined?

\subsection{Publications and Contributions}

All of the content of this thesis is based on the following three reviewed and published papers.

\section{Paper A: Learning Driver Behaviors Using A Gaussian Process Augmented State-Space Model.}

Anton Kullberg, Isaac Skog, and Gustaf Hendeby. Learning Driver Behaviors Using A Gaussian Process Augmented State-Space Model. In 2020 IEEE 23rd International Conference on Information Fusion (FUSION), Virtual, July 2020.

Paper A introduces the class of models studied in this thesis, namely augmented gray-box models that are both interpretable and adaptive. It provides a detailed derivation of the general inference scheme considered. It provides the first largescale example that illustrates one type of application where it is beneficial to combine an a priori established dynamical model with a generic black-box structure. Lastly, it shows that the augmented model reduces the overall estimation error as compared to using only the physically derived state-space model, which demonstrates the usefulness of the augmented model.

In Paper A, Isaac Skog (IS) and Gustaf Hendeby (GH) had the research idea and provided help with improving the manuscript. Anton Kullberg (AK) implemented the idea, carried out the simulation experiments and wrote the paper.

\section{Paper B: Online Joint State Inference and Learning of Partially Unknown State-Space Models.}

Anton Kullberg, Isaac Skog, and Gustaf Hendeby. Online Joint State Inference and Learning of Partially Unknown State-Space Models. IEEE Transactions on Signal Processing, 69:4149 - 4161, 2021. ISSN 19410476. doi: 10.1109/TSP.2021.3095709.

Paper B investigates the computational aspects of the proposed inference scheme when applied to large-scale problems. An approximate inference scheme that 
enables online inference in large-scale models, and which is essentially computationally invariant to the number of model parameters, is proposed. By using compactly supported radial basis functions and an approximate Kalman gain, the computational complexity is considerably reduced and is essentially determined by the support of the basis functions. The approximation works well when the system dynamics exhibit limited correlation between points well separated in the state-space domain. The method is shown to have competitive system dynamics estimation performance as compared to the method in Paper A and is real-time applicable even for models with a large number of parameters and problems of a large scale.

In Paper B, AK had the idea, implemented it, carried out the evaluations and wrote the paper. IS and GH provided research discussions and help with improving the manuscript.

\section{Paper C: Learning Motion Patterns in AIS Data and Detecting Anomalous Vessel Behavior.}

Anton Kullberg, Isaac Skog, and Gustaf Hendeby. Learning Motion Patterns in AIS Data and Detecting Anomalous Vessel Behavior. In 2021 IEEE 24th International Conference on Information Fusion (FUSION), Sun City/Virtual, Nov 2021.

Paper C provides a practical, real, example of scenarios of interest, highlighting a potential real-world use for the inference method developed in Paper B. It uses the method developed in Paper B to learn a model of nominal vessel routes from AIS data. It also proposes a method to detect anomalous behavior, which in the context of Paper $\mathrm{C}$ is defined as vessels not adhering to the nominal routes. The proposed method is shown to capture nominal vessel behavior from historical data and is subsequently able to detect artificially injected anomalous behavior.

In Paper C, AK, IS, and GH together had the idea. AK implemented it, carried out the evaluations and wrote the paper. IS and GH provided research discussions, technical support and help with improving the manuscript.

\subsection{Thesis Outline}

The thesis is divided into two parts, the first part, consisting of Chapters 2-5, presents background material and introduces the studied field of research to newcomers or readers that want to refresh their memory. Chapter 2 gives an introduction to function approximation and the two function parametrizations used in the publications presented in Part II. Chapter 3 introduces the notion of dynamical systems, and state and parameter estimation in such systems. Chapter 4 combines the two former chapters into the general inference scheme of interest in this thesis and provides thorough background knowledge to understand the content of the publications more easily. Chapter 5 concludes the first part of the thesis and highlights a few key areas in which to focus future research efforts. Part II contains the publications listed under Section 1.3. 



\section{2}

\section{Function Approximation}

This chapter introduces some fundamental techniques for approximating general functions. Before diving into these particular approximators, it is appropriate to briefly discuss what is meant by function approximation in the context of this thesis.

To begin, it is assumed that there exists a function $f^{0}(\mathbf{x}) \in \mathbb{R}$ of some input $\mathbf{x} \in \mathbb{R}^{n}$. The function takes $\mathbf{x}$ as input, and produces a real-valued response. The particular form of $f^{0}(\mathbf{x})$ is irrelevant, it only needs to exist. The function $f^{0}$ can not be queried perfectly, but there are noisy measurements of some function values, i.e.,

$$
y=f^{0}(\mathbf{x})+e,
$$

where $y \in \mathbb{R}$ is a measurement, and $e$ is a random noise corrupting the observed function values. We can assume that there exists $N$ such measurements and collect those measurements in a vector $\mathbf{y}_{N}$. The corresponding inputs are collected in the matrix $\mathbf{X}$. The goal is to compute an approximand $f$ of the function $f^{0}$, such that it resembles the true function as closely as possible, where the closeness is defined by some metric, e.g., the mean squared error

$$
\frac{1}{N} \sum_{i}^{N}\left[f^{0}\left(\mathbf{x}_{i}\right)-f\left(\mathbf{x}_{i}\right)\right]^{2} .
$$

Particularly, the interest here lies not with computing the approximand, but utilizing the resulting approximation to predict function values at new inputs.

The approximand $f(\mathbf{x})$ can be modeled in a variety of ways, two of which are discussed in this thesis. Section 2.1 introduces the Gaussian Process (GP) function description and highlights its strengths and limitations. Section 2.2 presents the Basis Function (BF) expansion description and how it relates to the GP. 


\subsection{Gaussian Processes}

There are mainly two ways of viewing a GP, the weight space view and the function space view. Here, the function space view is briefly presented, as it is the most common presentation in the literature. For a thorough introduction to GPs, see [17].

Technically, a GP is nothing less and nothing more than a collection of random variables. The defining property of a GP is that regardless of whatever subset of variables that is chosen from this collection, it is jointly Gaussian distributed. Formally, given an input $\mathbf{x}$, the real-valued function $f(\mathbf{x})$ given by

$$
f(\mathbf{x})=\mathcal{G} \mathcal{P}\left(m(\mathbf{x}), \kappa\left(\mathbf{x}, \mathbf{x}^{\prime}\right)\right),
$$

is a GP. The mean function $m(\mathbf{x})$ and covariance function (kernel) $\kappa\left(\mathbf{x}, \mathbf{x}^{\prime}\right)$ are given by

$$
\begin{aligned}
m(\mathbf{x}) & =\mathbb{E}[f(\mathbf{x})] \\
\kappa\left(\mathbf{x}, \mathbf{x}^{\prime}\right) & =\mathbb{E}\left[(f(\mathbf{x})-m(\mathbf{x}))\left(f(\mathbf{x})^{\prime}-m\left(\mathbf{x}^{\prime}\right)\right)\right] .
\end{aligned}
$$

For simplicity, the mean function $m(\mathbf{x})$ is assumed to be 0 , but can generally be used to include any prior information one may have about the function in question. Further, any measurements are assumed to be corrupted by Gaussian noise, i.e., in the model (2.1), the noise $e \sim \mathcal{N}\left(0, \sigma_{e}^{2}\right)$.

Now, let $\mathbf{f}^{*}$ be the function values at some arbitrary inputs $\mathbf{X}^{*}$. Then, the measurements $\mathbf{y}_{N}$ and function values $\mathbf{f}^{*}$ are jointly Gaussian distributed as

$$
\left(\begin{array}{c}
\mathbf{f}^{*} \\
\mathbf{y}_{N}
\end{array}\right) \mid \mathbf{X}, \mathbf{X}^{*} \sim \mathcal{N}\left(\left(\begin{array}{l}
\mathbf{0} \\
\mathbf{0}
\end{array}\right),\left(\begin{array}{cc}
K_{* *} & K_{* \mathbf{f}} \\
K_{\mathbf{f} *} & K_{\mathbf{f f}}+\sigma_{e}^{2} \mathbf{I}
\end{array}\right)\right) .
$$

Here, $\left[K_{* \mathbf{f}}\right]_{i, j}=\mathcal{k}\left(\left[\mathbf{X}^{*}\right]_{i},[\mathbf{X}]_{j}\right)$, i.e., matrices where each entry is an evaluation of the kernel $\mathcal{K}$ for the inputs related to the subscript variable. From this joint distribution, the conditional of $\mathbf{f}^{*}$ given $\mathbf{y}_{N}$, i.e., the posterior, can be obtained as

$$
\begin{aligned}
\mathbf{f}^{*} \mid \mathbf{y}_{N}, \mathbf{X}, \mathbf{X}^{*} & \sim \mathcal{N}\left(\overline{\mathbf{f}}^{*}, \operatorname{cov}\left(\mathbf{f}^{*}\right)\right) \\
\overline{\mathbf{f}}^{*} & =K_{* \mathbf{f}}\left[K_{\mathbf{f f}}+\sigma_{e}^{2} \mathbf{I}\right]^{-1} \mathbf{y}_{N} \\
\operatorname{cov}\left(\mathbf{f}^{*}\right) & =K_{* *}-K_{* \mathbf{f}}\left[K_{\mathbf{f f}}+\sigma_{e}^{2} \mathbf{I}\right]^{-1} K_{\mathbf{f} *} .
\end{aligned}
$$

Hence, the GP is a non-parametric method, as it uses the raw measurements themselves to predict new function values, in contrast to parametric methods which assume some parametric structure and summarize the data in the parameters.

All that is left to do is to specify the kernel $\kappa$ and the GP can then immediately be used to predict function values at any given input $\mathbf{x}^{\prime}$. A very common choice is the squared exponential kernel, given by

$$
\kappa\left(\mathbf{x}, \mathbf{x}^{\prime}\right)=\sigma_{f}^{2} \exp \left(-\frac{1}{2 l^{2}}\left\|\mathbf{x}-\mathbf{x}^{\prime}\right\|^{2}\right),
$$




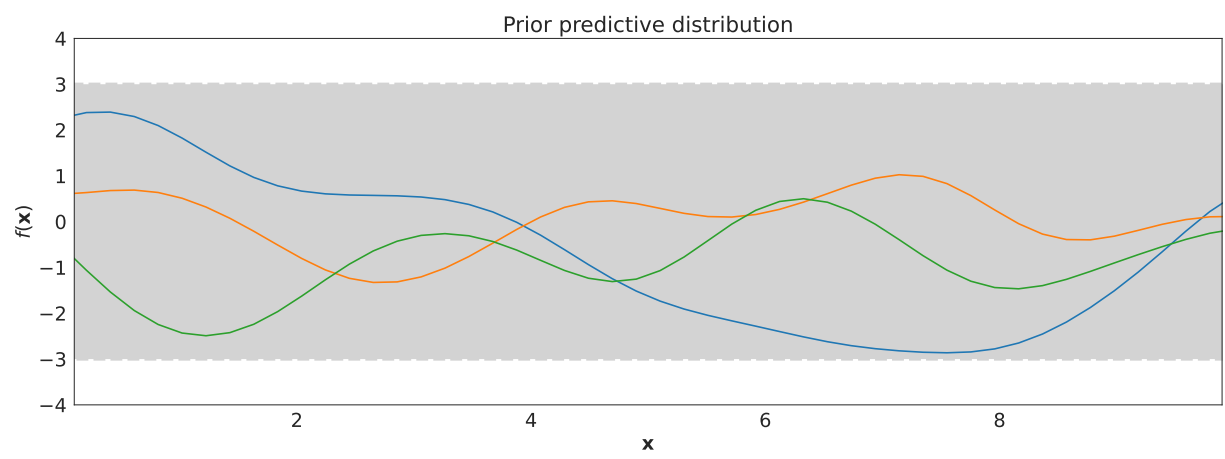

(a) Three random samples from GP prior

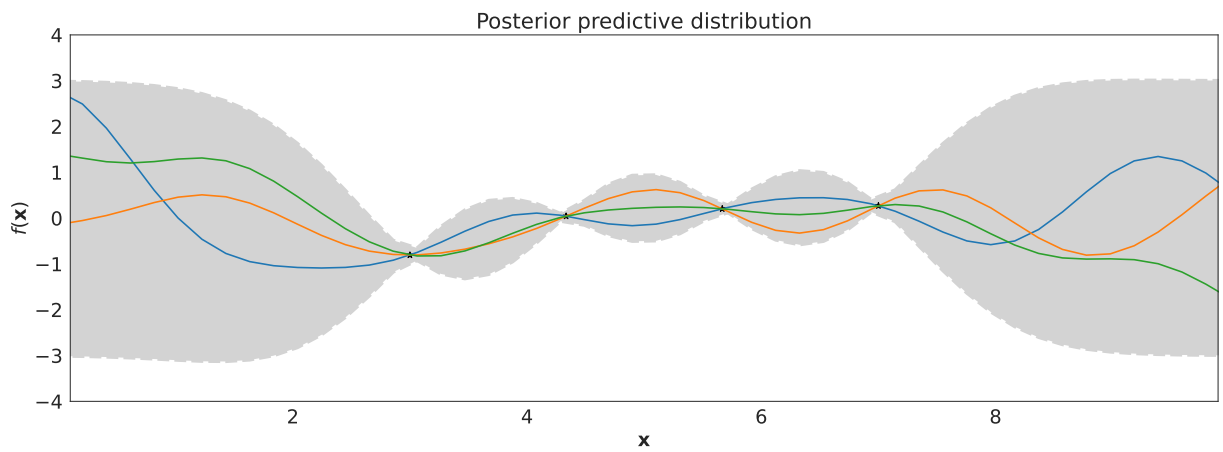

(b) Three random samples from GP posterior

Figure 2.1: Random samples from a GP prior and posterior predictive distribution. The gray confidence interval is the $3 \sigma$ interval for the prior and posterior predictive distribution, respectively. Clearly, the GP represents a distribution over functions, where the measurements guide the posterior toward the measured values.

where $l$ is called the characteristic length-scale and $\sigma_{f}^{2}$ is the signal variance. Of course, other choices exist that essentially changes how the GP extrapolates from the given data. This extrapolation implies a distribution over possible functions. To clearly illustrate this property, as well as the posterior predictive distribution, a visual example, akin to [17], is instructive.

\section{Example 2.1: Distribution over functions}

Assume a GP prior on the approximand $f(\mathbf{x})$, with mean $m(\mathbf{x})=\mathbf{0}$ and covariance given by $\kappa\left(\mathbf{x}, \mathbf{x}^{\prime}\right)$, where $\kappa$ is the squared exponential kernel with $\sigma_{f}=1, l=1$. This implies a predictive distribution which can be sampled from. Three such samples are shown in Figure 2.1a, where the prior predictive distribution is also shown with a $3 \sigma$ interval. Clearly, the three samples represent completely different functions, even though they share some properties, such as the smoothness. 
Now, four measurements are taken at equidistant points in the input space with a measurement noise that has standard deviation $\sigma_{e}=0.1$. Then, the posterior predictive distribution can be calculated according to (2.6) and subsequently sampled from. Again, three such samples are visualized in Figure 2.1b, where it is clear that the measurements guide the posterior predictive distribution toward the measured values, where the uncertainty is now low, whereas the predictive distribution is very similar to the prior far away from the measurements.

\subsubsection{Computational Challenges}

One particular problem that the GP formulation from the previous section suffers from, is its computational complexity. Particularly, note that the kernel matrix $K_{\mathrm{ff}} \in \mathbb{R}^{N \times N}$ in (2.6) needs to be inverted to obtain the posterior predictive distribution. Hence, the computational complexity of the ordinary GP implementation is of order $\mathcal{O}\left(N^{3}\right)$, which quickly becomes unmanageable as $N$ grows.

There are mainly two approaches to tackle this problem presented in the literature:

- Global approximation: Parametrize the GP with inducing inputs, see [16, 22].

- Local approximation: Divide the input space into distinct, assumed independent, regions and fit a GP in each region separately. See e.g. $[6,10,14]$.

Here, the first approach is used and one inducing input approximation is described. For an excellent review of multiple such approaches, see [16].

\subsubsection{Inducing Inputs}

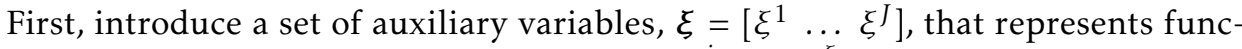
tion values at particular input locations, i.e., $\xi^{j}=f\left(\left[\mathbf{x}^{\xi}\right]_{j}\right)$. Note that the variables $\xi$, referred to as inducing variables, are just GP function values, similar to $\mathbf{f}$ and $\mathbf{f}^{*}$, and hence are jointly Gaussian distributed with $\mathbf{f}$ and $\mathbf{f}^{*}$. Particularly, it is possible to recover $p\left(\mathbf{f}, \mathbf{f}^{*}\right)$ by marginalizing $p\left(\mathbf{f}, \mathbf{f}^{*}, \boldsymbol{\xi}\right)$ w.r.t. $\xi$, i.e.,

$$
p\left(\mathbf{f}, \mathbf{f}^{*}\right)=\int p\left(\mathbf{f}, \mathbf{f}^{*}, \xi\right) d \xi=\int p\left(\mathbf{f}, \mathbf{f}^{*} \mid \xi\right) p(\xi) d \xi .
$$

To get any computational benefits, the joint conditional prior $p\left(\mathbf{f}, \mathbf{f}^{*} \mid \xi\right)$ is now approximated as $p\left(\mathbf{f}, \mathbf{f}^{*} \mid \xi\right) \simeq q\left(\mathbf{f}, \mathbf{f}^{*} \mid \xi\right)=q(\mathbf{f} \mid \xi) q\left(\mathbf{f}^{*} \mid \xi\right)$, i.e., the test values $\mathbf{f}^{*}$ are conditionally independent of the training values $\mathbf{f}$, conditioned on $\boldsymbol{\xi}$. Hence, the inducing variables $\xi$ act as parameters in which all of the information from the measurements is summarized. For the purposes in this thesis, additional approximations are necessary to fit into the estimation framework. Here, the Fully Independent Conditional (FIC) approximation is used, which was technically first introduced in [16] but should probably, as stated in [16], be attributed to [22]. 


\section{Fully Independent Conditional}

Essentially, the FIC approximation assumes that

$$
q(\mathbf{f} \mid \xi)=\prod_{i=1}^{N} p\left(\mathbf{f}_{i} \mid \xi\right),
$$

i.e., that the training values are conditionally independent, given $\xi$. This yields the likelihood

$$
p(\mathbf{y} \mid \mathbf{f}) \simeq q(\mathbf{y} \mid \xi)=\mathcal{N}\left(K_{\mathbf{f} \xi} K_{\xi \xi}^{-1} \xi, \operatorname{diag}[\underbrace{\left[K_{\mathbf{f f}}-K_{\mathbf{f} \xi} K_{\xi \xi}^{-1} K_{\xi \mathbf{f}}\right]}+\sigma^{2} \mathbf{I}) .\right.
$$

(*)

Hence, the measurements are completely independent, which is a necessity for the sequel. Further, note that the only difference from the exact likelihood is the diagonalization of $(*)$.

Now, the joint density of $\mathbf{y}$ and $\xi$ is given by

$$
\left(\begin{array}{l}
\xi \\
\mathbf{y}
\end{array}\right) \mid \mathbf{X}, \mathbf{x}^{\xi} \sim \mathcal{N}\left(\left(\begin{array}{l}
\mathbf{0} \\
\mathbf{0}
\end{array}\right),\left(\begin{array}{cc}
K_{\xi \xi} & K_{\xi \mathbf{f}} \\
K_{\mathbf{f} \xi} & \Lambda+Q_{\mathbf{f f}}
\end{array}\right)\right),
$$

where $Q_{a b}=K_{a \xi} K_{\xi \xi}^{-1} K_{\xi b}$ and $\Lambda=\operatorname{diag}\left[K_{\mathrm{ff}}-Q_{\mathrm{ff}}+\sigma^{2} \mathbf{I}\right]$. Thus, the posterior of $\xi$ conditioned on the measurements $\mathbf{y}$ is given by

$$
\begin{aligned}
p(\xi \mid \mathbf{y}) & =\mathcal{N}(\bar{\xi}, \operatorname{cov}(\xi)) \\
\bar{\xi} & =K_{\xi \mathbf{f}}\left(\Lambda+Q_{\mathbf{f f}}\right)^{-1} \mathbf{y} \\
\operatorname{cov}(\xi) & =K_{\xi \xi}-K_{\xi \mathbf{f}}\left(\Lambda+Q_{\mathrm{ff}}\right)^{-1} K_{\mathbf{f} \xi} .
\end{aligned}
$$

Further, FIC also assumes that the test values are conditionally independent given $\xi$ and factorize precisely as in (2.9). Thus, the predictive distribution conditioned on the measurements is given by

$$
\begin{aligned}
p\left(\mathbf{f}^{*} \mid \mathbf{y}\right) & =\int p\left(\mathbf{f}^{*} \mid \xi\right) p(\xi \mid \mathbf{y}) d \xi=\mathcal{N}\left(\overline{\mathbf{f}}^{*}, \operatorname{cov}\left(\mathbf{f}^{*}\right)\right) \\
\overline{\mathbf{f}}^{*} & =Q_{* \mathbf{f}}\left(\Lambda+Q_{\mathrm{ff}}\right)^{-1} \mathbf{y} \\
\operatorname{cov}\left(\mathbf{f}^{*}\right) & =\operatorname{diag}\left[K_{* *}-Q_{* *}\right]+Q_{* *}-Q_{* \mathbf{f}}\left(\Lambda+Q_{\mathrm{ff}}\right)^{-1} Q_{\mathbf{f} *}
\end{aligned}
$$

To highlight the effects of this approximation, a graphical example is provided in Example 2.2.

\section{Example 2.2: FIC approximation}

Assume that 200 noisy measurements are available of the function $f(x)=\frac{\sin (\pi x)}{\pi x}$ in the interval $x \in[-10,10]$. A squared exponential kernel is used for the GP with length scale $l=1$ and signal variance $\sigma_{f}=0.05$. From these 200 measurements, 30 input locations are chosen at random as inducing inputs and the posterior predictive distribution is calculated for both the FIC approximation as well as 


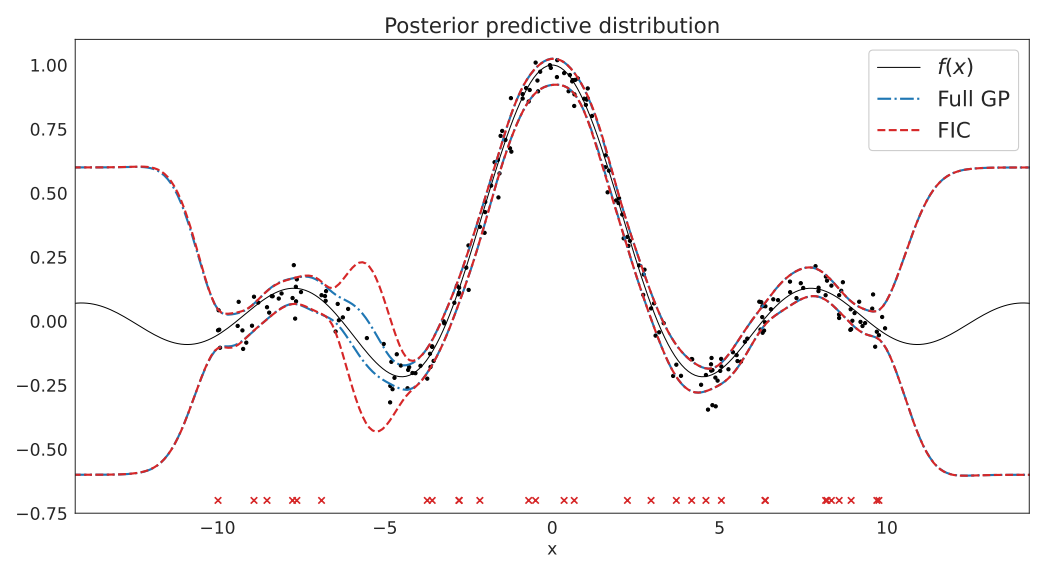

Figure 2.2: Posterior predictive distribution of a full GP and a FIC approximation. 200 noisy measurements, shown as black dots, with $\sigma=0.05$ were used to find the posteriors. 30 input locations were chosen at random from the training data to be used as inducing inputs $\mathbf{x}^{\xi}$ for the FIC approximation (visualized as red crosses). A squared exponential kernel was used with length scale $l=1$ and signal variance $\sigma_{f}=0.2$. Where there are an abundance of inducing inputs, the FIC approximation matches the full GP well, whereas it does not manage to capture the "true" predictive posterior at locations where there are no inducing inputs, e.g., around $x=-5$.

the full GP. The resulting posteriors are visualized in Figure 2.2, together with the true function and the measurements. The inducing inputs are shown as red crosses and the measurements are visualized by black dots.

Where there are an abundance of inducing inputs, the FIC approximation matches the full GP well, whereas it does not manage to capture the "true" predictive posterior at locations where there are no inducing inputs, e.g., around $x=-5$. Hence, as long as there are inducing inputs at locations of interest in the input space, the approximation works well.

As Example 2.2 shows, the choice of inducing inputs $\mathbf{x}^{\xi}$ is of importance to be able to approximate the true predictive posterior well. There are numerous approaches to select the locations of the inducing inputs, e.g., uniformly over the input space, selecting certain training data points as inducing variables (as in Example 2.2) [19], maximizing the marginal likelihood w.r.t. the inputs $\mathbf{x}^{\xi}$ $[22,26]$, etc. In this thesis, the primary method of choice is the first alternative. This is mainly for computational reasons, which is discussed in Paper B [8], and to avoid extra optimization steps. 


\subsection{Basis Function Expansion}

The core idea of the BF expansion is the construction

$$
f(\mathbf{x})=\sum_{j=1}^{J} \phi^{j}(\mathbf{x}) \theta^{j}=\phi^{\top}(\mathbf{x}) \theta,
$$

where $\phi^{j}$ is referred to as a basis function and $\theta^{j}$ is its corresponding weight.

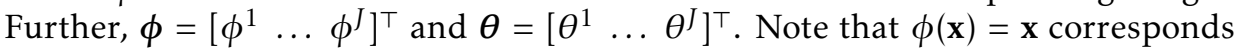
to a completely linear model.

The function $\phi$ is free to choose, but the focus in this thesis lies with the family of Radial Basis Functions (RBFs) [3], as they are universal approximators [15]. This family of functions depend solely on $\|\mathbf{x}-\xi\|$, i.e., the radial distance between the input and a parameter $\xi$, known as the BF center. An example of an RBF is the Gaussian RBF, given by

$$
\phi_{G}(\mathbf{x})=\exp \left(-\frac{\|\mathbf{x}-\xi\|^{2}}{2 l^{2}}\right)
$$

where $l$ is the length-scale.

Assuming the measurement model (2.1) with $\mathbf{e} \sim \mathcal{N}\left(0, \sigma_{e}^{2}\right)$, the measurement likelihood is given by

$$
p(\mathbf{y} \mid \boldsymbol{\theta})=\prod_{i=1}^{N} p\left(\mathbf{y}_{i} \mid \boldsymbol{\theta}\right)=\mathcal{N}\left(\mathbf{y} ; \boldsymbol{\phi}^{\top} \boldsymbol{\theta}, \sigma_{e}^{2} \mathbf{I}\right) .
$$

Further, selecting a prior on the parameters $\theta$ as $p(\theta)=\mathcal{N}\left(\theta ; 0, \sigma_{f}^{2} \mathbf{I}\right)$, yields the posterior

$$
\begin{aligned}
p(\boldsymbol{\theta} \mid \mathbf{y}) & =\frac{p(\mathbf{y} \mid \boldsymbol{\theta}) p(\boldsymbol{\theta})}{p(\mathbf{y})}=\mathcal{N}(\boldsymbol{\theta} ; \overline{\boldsymbol{\theta}}, \Sigma) \\
\overline{\boldsymbol{\theta}} & =\frac{1}{\sigma_{e}^{2}} \Sigma \boldsymbol{\phi} \mathbf{y} \\
\Sigma^{-1} & =\frac{1}{\sigma_{e}^{2}} \boldsymbol{\phi} \boldsymbol{\phi}^{\top}+\frac{1}{\sigma_{f}^{2}},
\end{aligned}
$$

where the dependence on $\mathbf{x}$ has been dropped for notational convenience. The posterior predictive distribution is then given by

$$
p\left(\mathbf{f}^{*} \mid \mathbf{y}, \mathbf{X}^{*}\right)=\mathcal{N}\left(\mathbf{f}^{*} ; \phi\left(\mathbf{X}^{*}\right)^{\top} \overline{\boldsymbol{\theta}}, \boldsymbol{\phi}^{\top}\left(\mathbf{X}^{*}\right) \Sigma \boldsymbol{\phi}\left(\mathbf{X}^{*}\right)\right)
$$




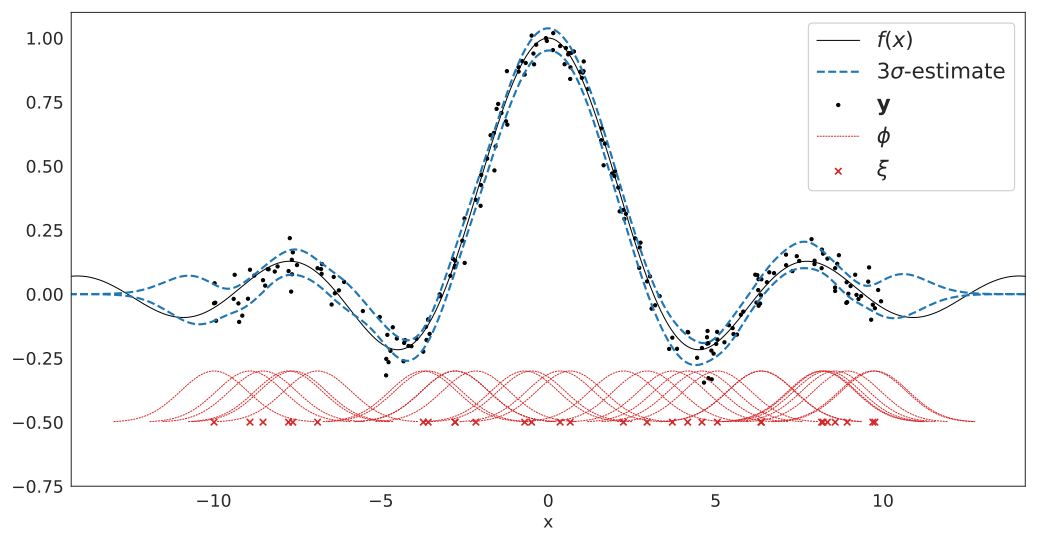

Figure 2.3: $3 \sigma$-interval of a BF expansion model with a Gaussian RBF, with length-scale $l=1.200$ noisy measurements, shown as black dots, with $\sigma=$ 0.05 were used to compute the parameters. 30 input locations were chosen at random from the training data to be used as BF center $\xi$, visualized as red crosses. Where there are an abundance of BFs, the estimated function matches the true function well. However, where the BFs have little to no influence (at the edges), the uncertainty is very low, which is opposite from what would be reasonable. This is generally not a big issue, as long as the BFs cover the entire input space reasonably well.

\section{Example 2.3: BF expansion regression}

Using the same construction as in Example 2.2, 30 data points were chosen at random as BF centers $\xi$. The length-scale of the BFs was set to $l=1$, similar to the kernel parameters in Example 2.2. The posterior of the parameters $\theta$ were found by (2.17) with $\sigma_{f}^{2}=0.2$. The posterior predictive $3 \sigma$ uncertainty is visualized in Figure 2.3. The measurements are illustrated with black dots, the BF centers as red crosses, and the actual BFs as the red dashed lines.

The BFs technically span all of the function support, since the Gaussian RBF has global support, i.e., $\phi_{G}(\mathbf{x})>0, \forall \mathbf{x}$. However, the predictive uncertainty approaches 0 far away from any basis functions, as $\phi_{G}(\mathbf{x}) \rightarrow 0$ when $|\mathbf{x}-\xi|$ increases. This is due to the deterministic relationship between $\mathbf{f}\left(\mathbf{x}^{*}\right)$ and $\theta$, recall (2.14). Particularly, note that the predictive uncertainty is given by (2.18) and will thus diminish as $\phi(\mathbf{x}) \rightarrow 0$. This is generally not that big of an issue as long as there are BFs with non-negligible values covering the entire input space.

The BF expansion (2.14) can also be interpreted as a GP. Particularly, if the prior $p(\theta)=\mathcal{N}\left(\theta ; 0, \sigma_{f}^{2}\right)$ is assumed, the expansion corresponds to a GP with the 
particular choice of kernel

$$
\kappa\left(\mathbf{x}, \mathbf{x}^{\prime}\right)=\sigma_{f}^{2} \sum_{j=1}^{J} \phi^{j}(\mathbf{x}) \phi^{j}\left(\mathbf{x}^{\prime}\right) .
$$

With the particular choice of BF as the Gaussian RBF (2.15), and letting the number of BFs $J \rightarrow \infty$, the equivalent kernel is the squared exponential (2.7). For a finite number of BFs and a specific prior on the weights $\theta$, the expansion instead corresponds to the deterministic inducing conditional approximation detailed in [16], originally attributed to [20]. For details, see Chapter 4 in [17], where the connection is thoroughly discussed. 



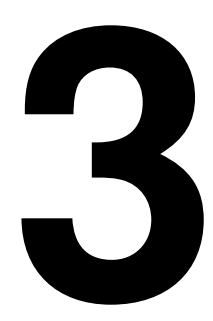

\section{Dynamical Systems and State Estimation}

A dynamical system is in essence a system which somehow evolves or changes over time. These systems can be physical entities, such as a road vehicle, a building or a coffee machine. They can also be nonphysical, such as the stock exchange, the housing market or a video game. This chapter introduces some fundamental aspects of dynamical systems, such as how they can be modeled and procedures for estimating properties of interest in these systems.

To this end, Section 3.1 presents the State-Space Model (SSM) in functional form as well as its probabilistic counterpart. Section 3.2 briefly explains state estimation from a Bayesian perspective. The content of the chapter is mainly based on $[4,18]$.

\subsection{State-Space Models}

One way of describing a dynamical system, is by constructing an SSM. An SSM describes the system in terms of its states. A state can represent essentially anything of interest, but generally changes over time. In the case when the dynamics of a car is to be modeled, a state could for instance be its velocity or tire load. In general, a continuous-time SSM can be of the form

$$
\begin{aligned}
\dot{\mathbf{x}} & =f(\mathbf{x}, \mathbf{u}, \mathbf{w}, \boldsymbol{\theta}) \\
\mathbf{y} & =h(\mathbf{x}, \mathbf{u}, \mathbf{e}, \boldsymbol{\theta}),
\end{aligned}
$$

where $\mathbf{x}$ refers to the state, $\mathbf{u}$ is a known input to the system, $\mathbf{w}$ is another stochastic component, often referred to as the process noise. Further, y denotes the measurements and $\mathbf{e}$ is a stochastic component, referred to as the measurement noise. Lastly, $\theta$ are model parameters that are either known a priori or that need to be estimated. 
The SSM (3.1) consists of a transition model (motion model) (3.1a), and a measurement model (sensor model) (3.1b). The transition model summarizes what is known about the considered system in a concise, mathematical description. It can, for instance, describe how acceleration relates to velocity or how a room is heated by a radiator. Most commonly, the transition model is specified through the use of physical and mathematical relationships, e.g., by use of simple Newtonian physics. The measurement model, on the other hand, describes what is being measured, and how that mathematically relates to the states of the system. It is completely defined by the sensors that are used to obtain the measurements and of what states of the system that are of interest. This essentially means that (3.1a) can be viewed as a user choice, whereas (3.1b) is defined by the system (and the choice of (3.1a)).

\subsubsection{Discrete State-Space Models}

To be able to use the continuous-time model (3.1) in a practical (computer) implementation, it is necessary to discretize it. The discretization process amounts to "sampling" the necessary entities (the state, input, etc.) at specific points in time. In essence, it alters the model description to

$$
\begin{aligned}
\mathbf{x}_{T+T_{s}} & =f_{T}\left(\mathbf{x}_{T}, \mathbf{u}_{T}, \mathbf{w}_{T}, \boldsymbol{\theta}\right) \\
\mathbf{y}_{T} & =h_{T}\left(\mathbf{x}_{T}, \mathbf{u}_{T}, \mathbf{e}_{T}, \boldsymbol{\theta}\right) .
\end{aligned}
$$

The important distinction between (3.2) and (3.1) concerns the transition models, (3.2a) and (3.1a). A loose, conceptual, description of (3.2a) might be: "given what I know about the state at time $T$, what will the state be at time $T+T_{S}$ ", where $T_{S}$ is referred to as the sampling interval. In contrast, (3.1a) can be loosely interpreted as "given the state, how fast is it changing". In the sequel, the model (3.2) is the main concern, as this is the most practically useful model. Henceforth, the notation shall be altered slightly to a more general "time index" $k$, where the sampling interval is implicitly included, i.e., if $k$ corresponds to $T$, then $k+1$ corresponds to $T+T_{s}$.

\subsubsection{Probabilistic Modeling}

The model (3.2) has an analogous probabilistic interpretation and can instead be expressed in terms of conditional probability density functions, i.e.,

$$
\begin{aligned}
\mathbf{x}_{k+1} & \sim p\left(\mathbf{x}_{k+1} \mid \mathbf{x}_{k}, \mathbf{u}_{k}, \boldsymbol{\theta}\right) \\
\mathbf{y}_{k} & \sim p\left(\mathbf{y}_{k} \mid \mathbf{x}_{k}, \mathbf{u}_{k}, \boldsymbol{\theta}\right) .
\end{aligned}
$$

Here, (3.3a) is referred to as the transition density and (3.3b) is the measurement density. Since the input $\mathbf{u}_{k}$ is assumed known, the explicit conditioning on $\mathbf{u}_{k}$ is dropped for notational convenience in the sequel.

The model (3.3) expresses the dynamical system in a formulation where it is convenient to reason about uncertainty. The uncertainty is captured by the resulting posterior probability density, which completely describes and encapsulates 
what belief that is currently held about the, in this case, states and parameters of the system.

\subsection{State Estimation}

The process of state estimation (inference) is here described in a probabilistic manner using the representation (3.3), but the algorithms may as well be derived using (3.2).

Before describing the state estimation process that is of interest here, it is assumed that the measurements arrive sequentially, i.e., the number of measurements grows over time. The interest herein then lies with computing an estimate of the state at a certain time $k$, given all the previous measurements, i.e., filtering. For notational brevity, the parameters $\theta$ are left out. Hence, the object of interest is the posterior distribution

$$
p\left(\mathbf{x}_{k} \mid \mathbf{y}_{1: k}\right)=\overbrace{\frac{p\left(\mathbf{y}_{k} \mid \mathbf{x}_{k}\right)}{p\left(\mathbf{y}_{k} \mid \mathbf{y}_{1: k-1}\right)}}^{(*)},
$$

where $\mathbf{y}_{1: k}$ is the sequence of measurements between time 1 and time $k$. The factor $(*)$ can be recognized as the measurement density (3.3b), whereas $(* *)$ is the predictive density given by

$$
p\left(\mathbf{x}_{k} \mid \mathbf{y}_{1: k-1}\right)=\int p\left(\mathbf{x}_{k} \mid \mathbf{x}_{k-1}\right) p\left(\mathbf{x}_{k-1} \mid \mathbf{y}_{1: k-1}\right) d \mathbf{x}_{k-1} .
$$

Here, the first factor can be recognized as the transition density (3.3a), whereas the second term is the posterior at time $k-1$. Hence, (3.4) and (3.5) define recursions which are alternated between prediction via (3.5), and incorporation of a new measurement via (3.4). Henceforth, (3.4) shall be referred to as the measurement update, as it incorporates the measurements into the estimate, and (3.5) is called the time update, as it "propagates" the state estimate forward in time.

Generally, the recursions do not have an analytical solution except for in a few special cases, most famously the Kalman filter (KF) [5], which is the solution in the case of a linear SSM with additive Gaussian noise, i.e., e, w are Gaussian distributed. If the model is instead nonlinear or non-Gaussian, approximations are necessary. There are mainly two ways of dealing with the lack of an analytical solution:

1. Approximate the model

2. Approximate the inference procedure.

Here, the first approach is dealt with, mainly because the second approach is generally more computationally intensive, especially in high dimensions, which is of interest here. 
One of the first approaches to dealing with nonlinear filtering was the Extended Kalman Filter (EKF). In summary, the model is linearized through the use of Taylor expansion at the current state estimate, and the ordinary KF updates are then applied. This necessitates the existence of the Jacobian, and thus we limit ourselves to differentiable models. The EKF has a computational complexity that is very close to the KF and it is thus a very (computationally) efficient algorithm. Assume that the model is given by

$$
\begin{aligned}
& \mathbf{x}_{k}=\mathbf{f}\left(\mathbf{x}_{k-1}\right)+\mathbf{g}\left(\mathbf{u}_{k-1}\right)+\mathbf{w}_{k-1} \\
& \mathbf{y}_{k}=\mathbf{h}\left(\mathbf{x}_{k}\right)+\mathbf{e}_{k},
\end{aligned}
$$

where $\mathbf{f}$ and $\mathbf{h}$ are general nonlinear functions. Further, $\mathbf{e}_{k} \sim \mathcal{N}(0, \mathbf{R}), \forall k$ and $\mathbf{w}_{k}=\sim \mathcal{N}(0, \mathbf{Q}), \forall k$. The EKF applied to this model is summarized in Algorithm 1 .

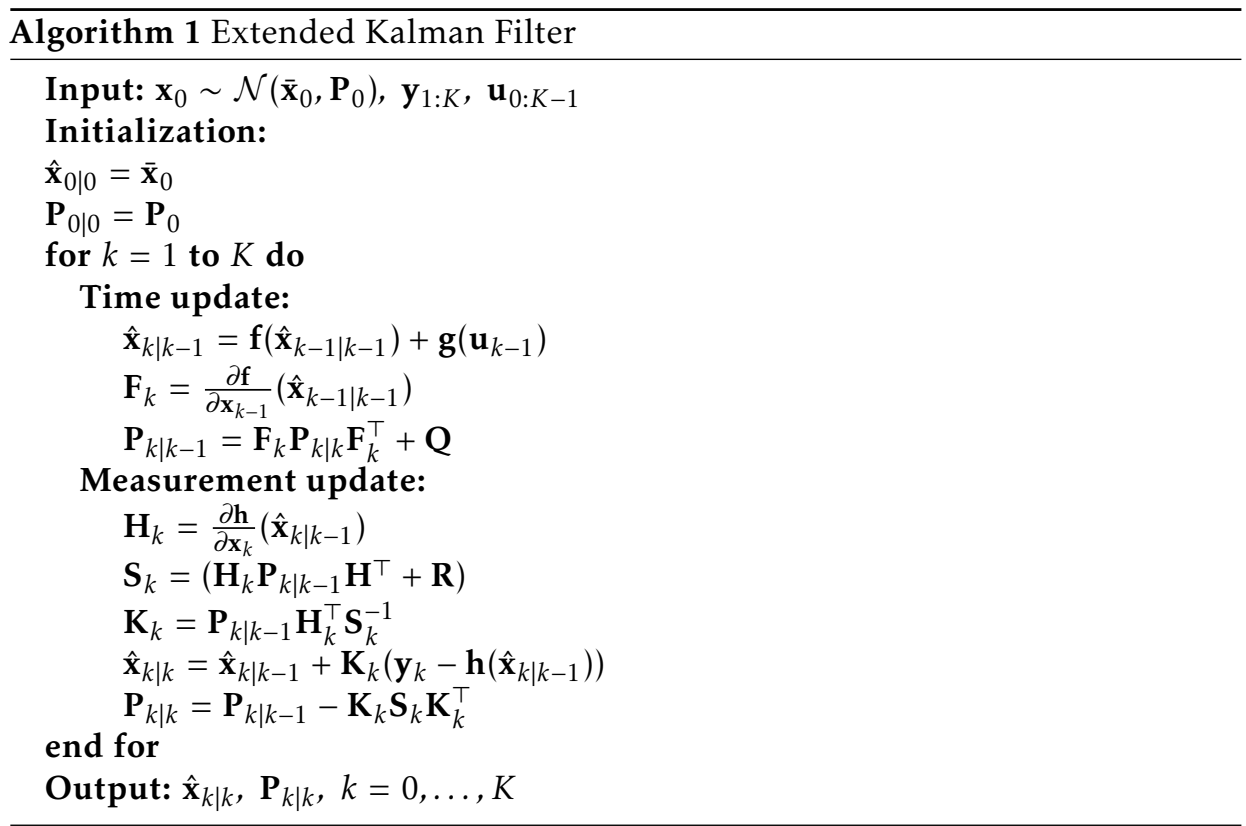

\subsection{Parameter Estimation}

Parameter estimation in SSMs differs slightly from the "static" case considered in Chapter 2. Particularly, the parameter estimates (often) depend on the state trajectories, which are themselves unknown. It is natural to think of two ways to deal with this (among others):

- Alternate between estimating the state trajectories and the parameters. Essentially, assume the parameters are given and estimate the state trajectories and vice versa for the parameter estimation. 
- Jointly estimate the states and the parameters.

For instance particle Markov Chain Monte-Carlo methods such as particle MetropolisHastings or particle Gibbs fall within the first category [1]. Here, the second alternative is considered as this naturally fits into the state estimation framework presented in Section 3.2. Example 3.1 presents one such approach, that is used in the remainder of this thesis.

\section{Example 3.1: Joint state and parameter estimation}

To illustrate the basic idea of the joint estimation procedure, consider the 1D-SSM

$$
\begin{aligned}
\mathbf{x}_{k+1} & =\theta \mathbf{x}_{k}+\mathbf{w}_{k} \\
\mathbf{y}_{k} & =\mathbf{x}_{k}+\mathbf{e}_{k} \\
\left(\begin{array}{c}
\mathbf{w}_{k} \\
\mathbf{e}_{k}
\end{array}\right) & \sim \mathcal{N}\left(\left[\begin{array}{l}
0 \\
0
\end{array}\right],\left[\begin{array}{cc}
\sigma_{w}^{2} & 0 \\
0 & \sigma_{e}^{2}
\end{array}\right]\right) .
\end{aligned}
$$

The equivalent probabilistic model is given by

$$
\begin{aligned}
p\left(\mathbf{x}_{k+1} \mid \mathbf{x}_{k}, \boldsymbol{\theta}\right) & =\mathcal{N}\left(\mathbf{x}_{k+1} ; \theta \mathbf{x}_{k}, \sigma_{w}^{2}\right) \\
p\left(\mathbf{y}_{k} \mid \mathbf{x}_{k}\right) & =\mathcal{N}\left(\mathbf{y}_{k} ; \mathbf{x}_{k}, \sigma_{e}^{2}\right) .
\end{aligned}
$$

Now, assume that $p\left(\theta_{k+1} \mid \theta_{k}\right)=\mathcal{N}\left(\theta_{k+1} ; \theta_{k}, \sigma_{\theta}^{2}\right)$, i.e. that the parameters follow a Gaussian random walk model. Thus, the parameters and the states can form an augmented state vector as $\mathbf{x}_{k}^{e}=\left[\mathbf{x}_{k}^{\top}, \theta_{k}^{\top}\right]^{\top}$. This augmented state vector now has the transition model

$$
\mathbf{x}_{k+1}^{e} \mid \mathbf{x}_{k}^{e} \sim \mathcal{N}\left(\mathbf{x}_{k+1}^{e} ;\left(\begin{array}{c}
\theta_{k} \mathbf{x}_{k} \\
\theta_{k}
\end{array}\right),\left(\begin{array}{cc}
\sigma_{w}^{2} & 0 \\
0 & \sigma_{\theta}^{2}
\end{array}\right)\right) .
$$

This augmented model is then treated as a nonlinear filtering problem and an EKF is applied to estimate both the states and the parameters of the original problem.

The original system was simulated for $K=50$ time steps with $\theta=0.9, \sigma_{w}=$ $0.2, \sigma_{e}=0.1$. The prior for the augmented state was set to $p\left(\mathbf{x}_{0}^{e}\right)=\mathcal{N}\left(\mathbf{x}_{0}^{e} ;\left[\begin{array}{ll}0 & 0.5\end{array}\right]^{\top}, \mathbf{I}\right)$ and the "process noise" affecting the parameters was set to $\sigma_{\theta}^{2}=.002$. The resulting state and parameter estimates are visualized in Figure 3.1. The state estimate is quite accurate, whereas the parameter estimate is slightly more uncertain, but seems to converge toward the true parameter. 

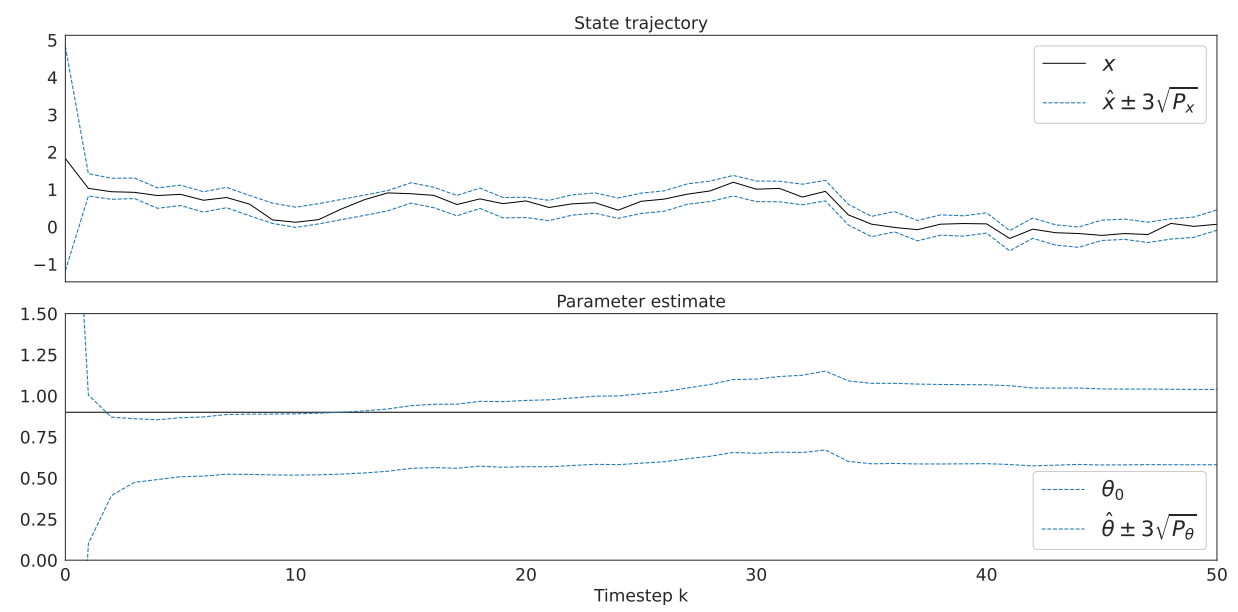

Figure 3.1: Joint estimation of the state and the parameter in the $1 D$ system (3.7). The state estimates are quite accurate whereas the parameter estimates are slightly more uncertain, but seems to converge toward the true parameter. 


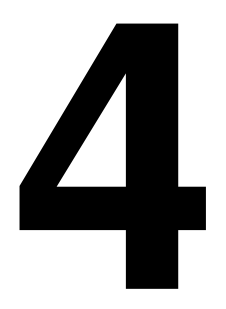

\section{Joint State Estimation and Function Approximation}

This chapter combines the methods discussed in Chapter 2 and Chapter 3 to approximate an unknown function affecting a dynamical system online. Such a function may for instance be physical such as wind or currents, or it may be nontangible such as driver behavior or regulations/laws. The only requirement is that the function values can be represented as a real-valued number, i.e., $g(x) \in \mathbb{R}$.

One way of describing such a system affected by an unknown function, is to let the system be described by

$$
\begin{aligned}
\mathbf{x}_{k+1} & =\mathbf{f}\left(\mathbf{x}_{k}, \mathbf{u}_{k}, \mathbf{w}_{k}, \mathbf{g}\left(\mathbf{x}_{k}, \mathbf{u}_{k}\right)\right) \\
\mathbf{y}_{k} & =\mathbf{h}\left(\mathbf{x}_{k}, \mathbf{u}_{k}, \mathbf{e}_{k}\right),
\end{aligned}
$$

where $\mathbf{g}\left(\mathbf{x}_{k}, \mathbf{u}_{k}\right)$ represents the function to be estimated. With a slight abuse of notation, the focus of this thesis is a special case of (4.1) of the form

$$
\begin{aligned}
\mathbf{x}_{k+1} & =\mathbf{f}\left(\mathbf{x}_{k}, \mathbf{u}_{k}\right)+\mathbf{g}_{\mathbf{f}}\left(\mathbf{w}_{k}+\mathbf{g}\left(\mathbf{x}_{k}, \mathbf{u}_{k}\right)\right) \\
\mathbf{y}_{k} & =\mathbf{h}\left(\mathbf{x}_{k}, \mathbf{u}_{k}\right)+\mathbf{e}_{k} .
\end{aligned}
$$

Here, $\mathbf{g}_{\mathbf{f}}$ describes how the unknown function $\mathbf{g}$ as well as the process noise $\mathbf{w}$ affects the system. The mapping $\mathbf{g}_{\mathbf{f}}$ is completely defined by the choice of transition model $\mathbf{f}$, which renders the unknown function $\mathbf{g}$ to be interpretable, given $\mathbf{f}$. To illustrate this property, Example 4.1 is provided as a concrete example.

\section{Example 4.1: Augmented constant velocity model}

Let the transition model $\mathbf{f}$ be given by a $1 \mathrm{D}$ constant velocity model and $\mathbf{x}=[p, v]^{\top}$, where $p$ is the position and $v$ is the velocity. The mapping $\mathbf{g}_{\mathbf{f}}$ is then linear and the complete transition model is given by

$$
\mathbf{x}_{k+1}=\left[\begin{array}{ll}
1 & T \\
0 & T
\end{array}\right] \mathbf{x}_{k}+\left[\begin{array}{c}
T^{2} / 2 \\
T
\end{array}\right]\left(\mathbf{w}_{k}+\mathbf{g}\left(\mathbf{x}_{k}\right)\right) .
$$


In (4.3), the function $\mathbf{g}\left(\mathbf{x}_{k}\right)$ is interpretable as the (deterministic) acceleration of the $1 \mathrm{D}$ system. Note that the process noise in this case will still deal with the stochasticity of the system.

Essentially, the construction (4.2) is a combination of a known part $\mathbf{f}$ and $\mathbf{g}_{\mathbf{f}}$, and an unknown part $\mathbf{g}$. It is stressed again that $\mathbf{f}$ and $\mathbf{g}_{\mathbf{f}}$ are chosen a priori and that they completely determine how $\mathbf{g}$ can be interpreted. Modeling $\mathbf{g}$ is done in two ways in this thesis, partly through the use of the FIC approximation to a GP, see Section 2.1.2, and also via a BF expansion, see Section 2.2. The latter method is illustrated in Example 4.2.

\section{Example 4.2: Online learning of particle acceleration}

Assume the transition model (4.3) with $\mathbf{g}$ modeled by a BF expansion as

$$
\mathbf{g}(\mathbf{x})=\phi(\mathbf{x})^{\top} \theta
$$

Let $\phi$ be given by the Gaussian RBF (2.15) and assume that $J=30$ BFs are equidistantly placed in the extent of the positional component $p$ of the state space. The model (4.3) is simulated for $K=100$ time steps with sampling time $T=0.1$. A deterministic acceleration component $\mathbf{g}_{0}$, is acting on the system and is given by

$$
\mathbf{g}_{0}(\mathbf{x})=\left\{\begin{array}{ll}
\sin (\pi p / 4) & 4<p<20 \\
0 & \text { otherwise }
\end{array}\right. \text {, }
$$

where $p$ is the position of the particle.

The system has an initial speed of $v=3 \mathrm{~m} / \mathrm{s}$ and an initial position of $p=0$. The parameters $\theta$ are assumed constant, and the length-scale of the RBF is set to $l=1$. Further, measurements of the particle position are obtained with a Gaussian noise with $\sigma_{e}=0.1$. Lastly, it is assumed that several particles travel through this region and as such, there are several particles to estimate the acceleration from. Particularly, it is assumed that $M=10$ particles travel through this region. Further, the particles are assumed to enter the region sequentially and the parameters are "passed" on from the previous to the next particle. An EKF is then used to jointly estimate the states of each particle and the constant parameters.

The resulting absolute error in position and velocity, as well as the estimate $\hat{\mathbf{g}}$ of $\mathbf{g}_{0}$ is visualized in Figure 4.1. Three trajectory errors and function estimates are presented for three different particles. Both the position and velocity error decreases with increasing particle index and the function estimate clearly improves over time, approaching the true function. 


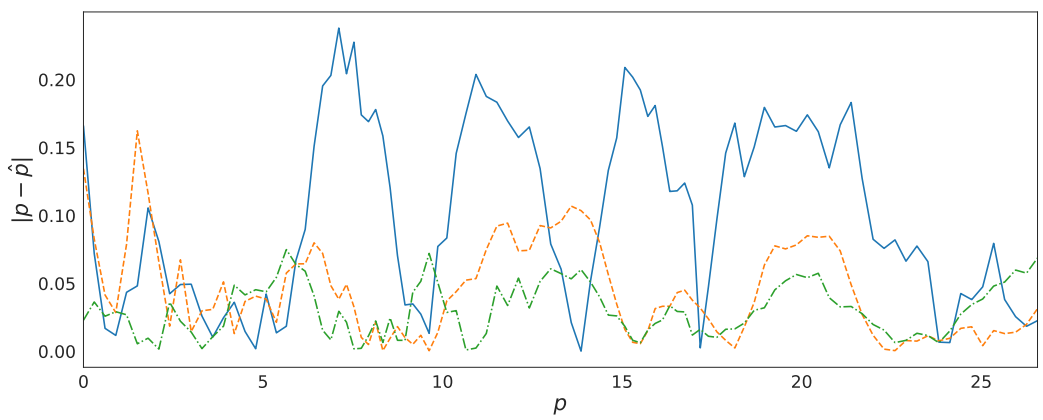

(a) Absolute position error, $|p-\hat{p}|$

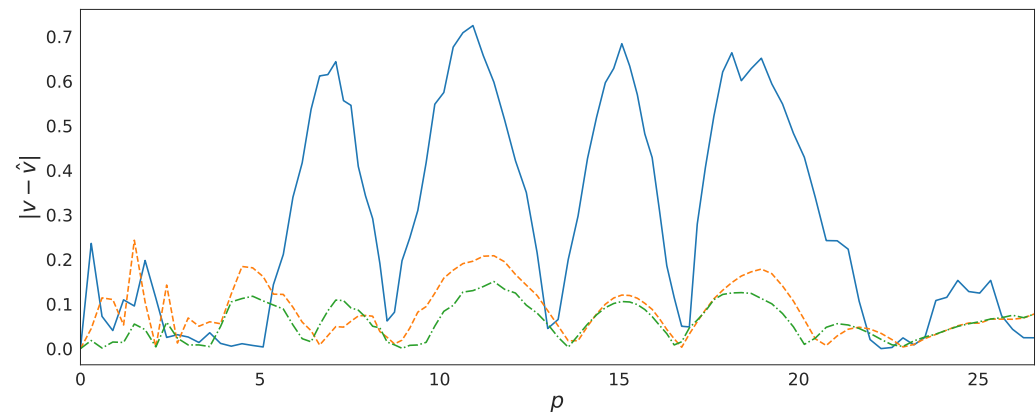

(b) Absolute velocity error, $|v-\hat{v}|$

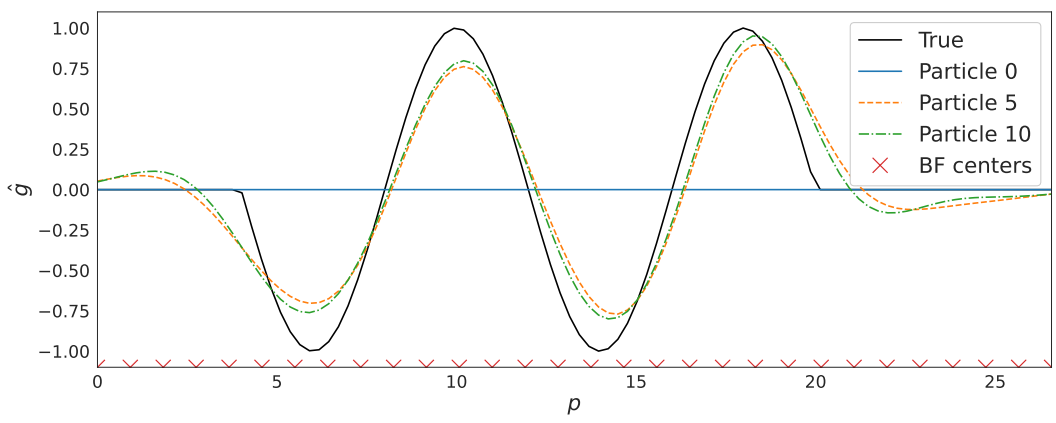

(c) Function estimate, $\hat{\mathbf{g}}$

Figure 4.1: Jointly estimated states and acceleration function of a $1 D$ particle system, with states $\mathbf{x}=[p, v] . M=10$ particles were simulated affected by the same accelerating force. Measurements of the particles were sequentially used to estimate the accelerating function and the state trajectory of each particle. Three trajectory errors and function estimates are presented for three different particles. Both the position, see (a), and velocity error, see (b), decrease with an increasing particle index and the function estimate, see (c), improves over time, approaching the true function. 



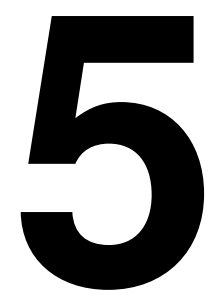

\section{Concluding Remarks}

The first part of this thesis has introduced two function approximators, the GP, see Section 2.1, and the BF, see Section 2.2, and the connections between the two function approximations has been highlighted. Further, a description of the specific approximations that lay the foundation for the methods in the publications in Part II has been presented. In Chapter 3, an introduction to dynamical systems and state estimation in a filtering setting, i.e., when measurements up until the current time are available, has been provided. Lastly, Chapter 4 combined the function approximators from Chapter 2 and the state-space models from Chapter 3 to describe an inference procedure for the joint estimation of the model parameters and the dynamical states. It did so through the introduction of the SSM+BF model, which is another parametrization of the GPSSM model, see e.g., $[23,25]$. The first part of this thesis should serve as an adequate introduction to assimilate the material in the publications in the second part.

\subsection{Conclusions}

The publications in the second part of this thesis extend the methods from part one and particularly exploit structure in the models to efficiently learn models with tens of thousands of parameters or more. Two different, although highly related, augmented gray-box models were used throughout the publications. The first consists of an SSM augmented with a sparse GP based on the FIC approximation, see Section 2.1.2 and Paper A. The second is an SSM augmented with an RBF expansion, see Section 2.2 and Paper B. The two models were shown to have improved estimation performance, in a mean squared error sense, as compared to using just the SSM, see Papers A and B.

In Paper $\mathrm{B}$, the computational complexity of the inference scheme applied to the two models has been analyzed. The SSM augmented with an RBF expansion 
was modified to use compactly supported RBFs. Because of the compact support, only a small number of RBFs are non-zero at any given time, which was shown to lower the computational complexity for prediction. However, the predictions still induce a correlation between the RBF weights and the state $\mathbf{x}$. Thus, the measurement update was modified to only update the weights of BFs that were recently used for prediction. This was shown to significantly reduce the computational complexity and rendered a method which is real-time applicable to models with tens of thousand of parameters or more. It turned out that the method is nearly computationally invariant to the number of parameters. Further, the function approximation and state estimation performance of the modified scheme was shown to be highly competitive with the original formulation.

Lastly, in Paper C, the SSM augmented with the compactly supported RBFs was used to learn nominal vessel behavior in a harbor area in Västervik, Sweden. A method for detecting anomalous behavior, i.e., when the model does not adequately describe the vessel behavior, was then proposed. After initially learning an expected vessel behavior from historical data, the detection method was shown to accurately detect artificially injected anomalies.

\subsection{Future Work}

One problematic aspect of the methods described in this thesis, which is also highlighted in Paper A, is that it cannot handle multimodal functions, i.e., when there is conflicting information about what the output "should" be, given the input. Finding an efficient way of describing this, that does not significantly impact the computational performance, can further improve the usefulness of the models presented here.

Another potential avenue to explore, which was alluded to in Section 1.1, is to actually deploy the models in a motion planning scenario, where the motion patterns are actively learned in real-time and are reused to efficiently predict the motion of other vehicles in, for instance, a traffic scenario.

Further, while the regular grids of basis functions considered in this thesis is practical from the point of view of the user, it could be beneficial, both computationally as well as in a mean squared error sense, to optimize the quantity and location of the basis functions. Optimization of the locations has been considered in, e.g., [26] which considered it as a continuous optimization problem whereas [19] greedily included more and more training data points into the set of inducing inputs based on some score heuristic. An interesting approach to selecting both quantity and location can be found in [27] where inclusion of inducing inputs into the model is handled in a probabilistic manner.

Lastly, a thorough investigation into the approximatory power of a particular BF expansion or GP description could potentially provide a "minimal" model, while preserving the, in a root mean squared error sense, performance of the function approximation. In this way, one could, hopefully in an adaptive setting, find the exact number of BFs or inducing points necessary to represent the particular function of interest at the current time. 


\section{Bibliography}

[1] Christophe Andrieu, Arnaud Doucet, and Roman Holenstein. Particle Markov chain Monte Carlo methods. Journal of the Royal Statistical Society Series B, 72(3):269-342, 2010. ISSN 13697412. doi: 10.1111/j.1467-9868. 2009.00736.x.

[2] Karl Berntorp. Online Bayesian Inference and Learning of Gaussian-Process State-Space Models. Automatica, 129, 2021. doi: 10.1016/j.automatica. 2021.109613.

[3] Martin D. Buhmann. Radial Basis Functions: Theory and Implementations. Cambridge University Press, 2003. ISBN 9788578110796. doi: 10.1017/ CBO9781107415324.004.

[4] Fredrik Gustafsson. Statistical Sensor Fusion. Studentlitteratur AB, 2012. ISBN 9789144077321.

[5] R. E. Kalman. A new approach to linear filtering and prediction problems. Transactions of the ASME - Journal of Basic Engineering, 82(1):35-45, 1960. ISSN 1528901X. doi: 10.1115/1.3662552.

[6] Manon Kok and Arno Solin. Scalable Magnetic Field SLAM in 3D Using Gaussian Process Maps. In 2018 IEEE 21st International Conference on Information Fusion (FUSION), pages 1353-1360, Cambridge, UK, July 2018. ISBN 9780996452762. doi: 10.23919/ICIF.2018.8455789.

[7] Anton Kullberg, Isaac Skog, and Gustaf Hendeby. Learning Driver Behaviors Using A Gaussian Process Augmented State-Space Model. In 2020 IEEE 23rd International Conference on Information Fusion (FUSION), Virtual, July 2020.

[8] Anton Kullberg, Isaac Skog, and Gustaf Hendeby. Online Joint State Inference and Learning of Partially Unknown State-Space Models. IEEE Transactions on Signal Processing, 69:4149 - 4161, 2021. ISSN 19410476. doi: 10.1109/TSP.2021.3095709. 
[9] Anton Kullberg, Isaac Skog, and Gustaf Hendeby. Learning Motion Patterns in AIS Data and Detecting Anomalous Vessel Behavior. In 2021 IEEE 24th International Conference on Information Fusion (FUSION), Sun City/Virtual, Nov 2021.

[10] Armin Lederer, Alejandro Jose Ordonez Conejo, Korbinian Maier, Wenxin Xiao, and Sandra Hirche. Real-Time Regression with Dividing Local Gaussian Processes. Unpublished, June 2020. URL http: / / arxiv.org/abs / 2006.09446.

[11] L Ljung. System Identification: Theory for the User. Pearson Education, second edition, 1998. ISBN 9780132440530.

[12] Fredrik Ljungberg. Estimation of Nonlinear Greybox Models for Marine Applications. Licentiate thesis no 1880, Department of Electrical Engineering, Linköpings universitet, Sweden, 2020.

[13] Magnus Malmström. Uncertainties in Neural Networks: A System Identification Approach. Licentiate thesis no 1902, Department of Electrical Engineering, Linköpings universitet, Sweden, 2021.

[14] Duy Nguyen-Tuong, Jan Peters, and Matthias Seeger. Local Gaussian process regression for real time online model learning and control. In Advances in Neural Information Processing Systems, volume 21, pages 1193-1200, 2009. ISBN 9781605609492.

[15] J. Park and I. W. Sandberg. Universal Approximation Using Radial-BasisFunction Networks. Neural Computation, 3(2):246-257, 1991. ISSN 08997667. doi: 10.1162/neco.1991.3.2.246.

[16] Joaquin Quiñonero-Candela and Carl Edward Rasmussen. A Unifying View of Sparse Approximate Gaussian Process Regression. Journal of Machine Learning Research, 6:1939-1959, 2005. ISSN 15337928.

[17] Carl Edward Rasmussen and Christopher K. I. Williams. Gaussian Processes for Machine Learning. MIT Press, 2006.

[18] Simo Särkkä. Bayesian Filtering and Smoothing. Cambridge University Press, 2010. ISBN 9781139344203. doi: 10.1017/CBO9781139344203.

[19] Matthias Seeger, Christopher K I Williams, and Neil D Lawrence. Fast Forward Selection to Speed Up Sparse Gaussian Process Regression. In Ninth International Workshop on Artificial Intelligence and Statistics, pages 254261. PMLR, 2003.

[20] B. W. Silverman. Some Aspects of the Spline Smoothing Approach to NonParametric Regression Curve Fitting. Journal of the Royal Statistical Society Series B, 47(1):1-21, 1985. ISSN 0035-9246. doi: 10.1111/j.2517-6161.1985. tb01327.x. 
[21] J. Sjöberg, H. Hjalmarsson, and L. Ljung. Neural Networks in System Identification. IFAC Proceedings Volumes, 27(8):359-382, 1994. ISSN 14746670. doi: 10.1016/s1474-6670(17)47737-8.

[22] Edward Snelson and Zoubin Ghahramani. Sparse Gaussian Processes using Pseudo-inputs. In Advances in Neural Information Processing Systems, volume 18, pages 1257-1264. MIT Press, 2006.

[23] Arno Solin and Simo Särkkä. Hilbert space methods for reduced-rank Gaussian process regression. Statistics and Computing, 30(2):419-446, 2020. ISSN 15731375. doi: 10.1007/s11222-019-09886-w.

[24] Andreas Svensson and Thomas B. Schön. A flexible state-space model for learning nonlinear dynamical systems. Automatica, 2017. ISSN 00051098. doi: 10.1016/j.automatica.2017.02.030.

[25] Andreas Svensson, Arno Solin, Simo Särkkä, and Thomas B. Schön. Computationally Efficient Bayesian Learning of Gaussian Process State Space Models. In AISTATS 2016, pages 213-221, Cadiz, Spain, May 2016.

[26] Michalis K Titsias. Variational Learning of Inducing Variables in Sparse Gaussian Processes. In David van Dyk and Max Welling, editors, AISTATS 2009, volume 5, pages 567-574, Clearwater, Florida, April 2009. JMLR.

[27] Anders Kirk Uhrenholt, Valentin Charvet, and Bjørn Sand Jensen. Probabilistic selection of inducing points in sparse Gaussian processes. In 37th Conference on Uncertainty in Artificial Intelligence (UAI 2021), Virtual, 2021.

[28] Clas Veibäck, Jonatan Olofsson, Tom Rune Lauknes, and Gustaf Hendeby. Learning Target Dynamics While Tracking Using Gaussian Processes. IEEE Transactions on Aerospace and Electronic Systems, 9251:1-10, 2019. doi: 10.1109/TAES.2019.2948699. 



\section{Part II}

\section{Publications}




\section{Papers}

The papers associated with this thesis have been removed for copyright reasons. For more details about these see:

https://doi.org/10.3384/9789179291426 


\section{Licentiate Theses \\ Division of Automatic Control \\ Linköping University}

P. Andersson: Adaptive Forgetting through Multiple Models and Adaptive Control of Car Dynamics. Thesis No. 15, 1983.

B. Wahlberg: On Model Simplification in System Identification. Thesis No. 47, 1985.

A. Isaksson: Identification of Time Varying Systems and Applications of System Identification to Signal Processing. Thesis No. 75, 1986.

G. Malmberg: A Study of Adaptive Control Missiles. Thesis No. 76, 1986.

S. Gunnarsson: On the Mean Square Error of Transfer Function Estimates with Applications to Control. Thesis No. 90, 1986.

M. Viberg: On the Adaptive Array Problem. Thesis No. 117, 1987.

K. Ståhl: On the Frequency Domain Analysis of Nonlinear Systems. Thesis No. 137, 1988.

A. Skeppstedt: Construction of Composite Models from Large Data-Sets. Thesis No. 149, 1988.

P. A. J. Nagy: MaMiS: A Programming Environment for Numeric/Symbolic Data Processing. Thesis No. 153, 1988.

K. Forsman: Applications of Constructive Algebra to Control Problems. Thesis No. 231, 1990.

I. Klein: Planning for a Class of Sequential Control Problems. Thesis No. 234, 1990.

F. Gustafsson: Optimal Segmentation of Linear Regression Parameters. Thesis No. 246, 1990.

H. Hjalmarsson: On Estimation of Model Quality in System Identification. Thesis No. 251, 1990.

S. Andersson: Sensor Array Processing; Application to Mobile Communication Systems and Dimension Reduction. Thesis No. 255, 1990.

K. Wang Chen: Observability and Invertibility of Nonlinear Systems: A Differential Algebraic Approach. Thesis No. 282, 1991.

J. Sjöberg: Regularization Issues in Neural Network Models of Dynamical Systems. Thesis No. 366, 1993.

P. Pucar: Segmentation of Laser Range Radar Images Using Hidden Markov Field Models. Thesis No. 403, 1993.

H. Fortell: Volterra and Algebraic Approaches to the Zero Dynamics. Thesis No. 438, 1994.

T. McKelvey: On State-Space Models in System Identification. Thesis No. 447, 1994.

T. Andersson: Concepts and Algorithms for Non-Linear System Identifiability. Thesis No. 448, 1994.

P. Lindskog: Algorithms and Tools for System Identification Using Prior Knowledge. Thesis No. 456, 1994.

J. Plantin: Algebraic Methods for Verification and Control of Discrete Event Dynamic Systems. Thesis No. 501, 1995.

J. Gunnarsson: On Modeling of Discrete Event Dynamic Systems, Using Symbolic Algebraic Methods. Thesis No. 502, 1995.

A. Ericsson: Fast Power Control to Counteract Rayleigh Fading in Cellular Radio Systems. Thesis No. 527, 1995.

M. Jirstrand: Algebraic Methods for Modeling and Design in Control. Thesis No. 540, 1996.

K. Edström: Simulation of Mode Switching Systems Using Switched Bond Graphs. Thesis No. 586, 1996. 
J. Palmqvist: On Integrity Monitoring of Integrated Navigation Systems. Thesis No. 600, 1997.

A. Stenman: Just-in-Time Models with Applications to Dynamical Systems. Thesis No. 601, 1997.

M. Andersson: Experimental Design and Updating of Finite Element Models. Thesis No. 611, 1997.

U. Forssell: Properties and Usage of Closed-Loop Identification Methods. Thesis No. 641, 1997.

M. Larsson: On Modeling and Diagnosis of Discrete Event Dynamic systems. Thesis No. 648, 1997.

N. Bergman: Bayesian Inference in Terrain Navigation. Thesis No. 649, 1997.

V. Einarsson: On Verification of Switched Systems Using Abstractions. Thesis No. 705, 1998.

J. Blom, F. Gunnarsson: Power Control in Cellular Radio Systems. Thesis No. 706, 1998.

P. Spångéus: Hybrid Control using LP and LMI methods - Some Applications. Thesis No. 724, 1998.

M. Norrlöf: On Analysis and Implementation of Iterative Learning Control. Thesis No. 727, 1998.

A. Hagenblad: Aspects of the Identification of Wiener Models. Thesis No. 793, 1999.

F. Tjärnström: Quality Estimation of Approximate Models. Thesis No. 810, 2000.

C. Carlsson: Vehicle Size and Orientation Estimation Using Geometric Fitting. Thesis No. 840, 2000.

J. Löfberg: Linear Model Predictive Control: Stability and Robustness. Thesis No. 866, 2001.

O. Härkegård: Flight Control Design Using Backstepping. Thesis No. 875, 2001.

J. Elbornsson: Equalization of Distortion in A/D Converters. Thesis No. 883, 2001.

J. Roll: Robust Verification and Identification of Piecewise Affine Systems. Thesis No. 899, 2001.

I. Lind: Regressor Selection in System Identification using ANOVA. Thesis No. 921, 2001.

R. Karlsson: Simulation Based Methods for Target Tracking. Thesis No. 930, 2002.

P.-J. Nordlund: Sequential Monte Carlo Filters and Integrated Navigation. Thesis No. 945, 2002.

M. Östring: Identification, Diagnosis, and Control of a Flexible Robot Arm. Thesis No. 948, 2002.

C. Olsson: Active Engine Vibration Isolation using Feedback Control. Thesis No. 968, 2002.

J. Jansson: Tracking and Decision Making for Automotive Collision Avoidance. Thesis No. 965, 2002.

N. Persson: Event Based Sampling with Application to Spectral Estimation. Thesis No. 981, 2002.

D. Lindgren: Subspace Selection Techniques for Classification Problems. Thesis No. 995, 2002.

E. Geijer Lundin: Uplink Load in CDMA Cellular Systems. Thesis No. 1045, 2003.

M. Enqvist: Some Results on Linear Models of Nonlinear Systems. Thesis No. 1046, 2003.

T. Schön: On Computational Methods for Nonlinear Estimation. Thesis No. 1047, 2003.

F. Gunnarsson: On Modeling and Control of Network Queue Dynamics. Thesis No. 1048, 2003.

S. Björklund: A Survey and Comparison of Time-Delay Estimation Methods in Linear Systems. Thesis No. 1061, 2003. 
M. Gerdin: Parameter Estimation in Linear Descriptor Systems. Thesis No. 1085, 2004.

A. Eidehall: An Automotive Lane Guidance System. Thesis No. 1122, 2004.

E. Wernholt: On Multivariable and Nonlinear Identification of Industrial Robots. Thesis No. 1131, 2004.

J. Gillberg: Methods for Frequency Domain Estimation of Continuous-Time Models. Thesis No. 1133, 2004.

G. Hendeby: Fundamental Estimation and Detection Limits in Linear Non-Gaussian Systems. Thesis No. 1199, 2005.

D. Axehill: Applications of Integer Quadratic Programming in Control and Communication. Thesis No. 1218, 2005.

J. Sjöberg: Some Results On Optimal Control for Nonlinear Descriptor Systems. Thesis No. 1227, 2006.

D. Törnqvist: Statistical Fault Detection with Applications to IMU Disturbances. Thesis No. 1258, 2006.

H. Tidefelt: Structural algorithms and perturbations in differential-algebraic equations. Thesis No. 1318, 2007.

S. Moberg: On Modeling and Control of Flexible Manipulators. Thesis No. 1336, 2007.

J. Wallén: On Kinematic Modelling and Iterative Learning Control of Industrial Robots. Thesis No. 1343, 2008.

J. Harju Johansson: A Structure Utilizing Inexact Primal-Dual Interior-Point Method for Analysis of Linear Differential Inclusions. Thesis No. 1367, 2008.

J. D. Hol: Pose Estimation and Calibration Algorithms for Vision and Inertial Sensors. Thesis No. 1370, 2008.

H. Ohlsson: Regression on Manifolds with Implications for System Identification. Thesis No. 1382, 2008.

D. Ankelhed: On low order controller synthesis using rational constraints. Thesis No. 1398, 2009.

P. Skoglar: Planning Methods for Aerial Exploration and Ground Target Tracking. Thesis No. 1420, 2009.

C. Lundquist: Automotive Sensor Fusion for Situation Awareness. Thesis No. 1422, 2009.

C. Lyzell: Initialization Methods for System Identification. Thesis No. 1426, 2009.

R. Falkeborn: Structure exploitation in semidefinite programming for control. Thesis No. 1430, 2010.

D. Petersson: Nonlinear Optimization Approaches to $\mathcal{H}_{2}$-Norm Based LPV Modelling and Control. Thesis No. 1453, 2010.

Z. Sjanic: Navigation and SAR Auto-focusing in a Sensor Fusion Framework. Thesis No. 1464, 2011.

K. Granström: Loop detection and extended target tracking using laser data. Thesis No. 1465, 2011.

J. Callmer: Topics in Localization and Mapping. Thesis No. 1489, 2011.

F. Lindsten: Rao-Blackwellised particle methods for inference and identification. Thesis No. 1480, 2011.

M. Skoglund: Visual Inertial Navigation and Calibration. Thesis No. 1500, 2011.

S. Khoshfetrat Pakazad: Topics in Robustness Analysis. Thesis No. 1512, 2011.

P. Axelsson: On Sensor Fusion Applied to Industrial Manipulators. Thesis No. 1511, 2011.

A. Carvalho Bittencourt: On Modeling and Diagnosis of Friction and Wear in Industrial Robots. Thesis No. 1516, 2012.

P. Rosander: Averaging level control in the presence of frequent inlet flow upsets. Thesis No. 1527, 2012. 
N. Wahlström: Localization using Magnetometers and Light Sensors. Thesis No. 1581, 2013.

R. Larsson: System Identification of Flight Mechanical Characteristics. Thesis No. 1599, 2013.

Y. Jung: Estimation of Inverse Models Applied to Power Amplifier Predistortion. Thesis No. 1605, 2013.

M. Syldatk: On Calibration of Ground Sensor Networks. Thesis No. 1611, 2013.

M. Roth: Kalman Filters for Nonlinear Systems and Heavy-Tailed Noise. Thesis No. 1613, 2013.

D. Simon: Model Predictive Control in Flight Control Design - Stability and Reference Tracking. Thesis No. 1642, 2014.

J. Dahlin: Sequential Monte Carlo for inference in nonlinear state space models. Thesis No. 1652, 2014.

M. Kok: Probabilistic modeling for positioning applications using inertial sensors. Thesis No. 1656, 2014.

J. Linder: Graybox Modelling of Ships Using Indirect Input Measurements. Thesis No. 1681, 2014.

G. Mathai: Direction of Arrival Estimation of Wideband Acoustic Wavefields in a Passive Sensing Environment. Thesis No. 1721, 2015.

I. Nielsen: On Structure Exploiting Numerical Algorithms for Model Predictive Control. Thesis No. 1727, 2015.

C. Veibäck: Tracking of Animals Using Airborne Cameras. Thesis No. 1761, 2016.

N. Evestedt: Sampling Based Motion Planning for Heavy Duty Autonomous Vehicles. Thesis No. 1762, 2016.

H. Nyqvist: On Pose Estimation in Room-Scaled Environments. Thesis No. 1765, 2016.

Y. Zhao: Position Estimation in Uncertain Radio Environments and Trajectory Learning. Thesis No. 1772, 2017.

P. Kasebzadeh: Parameter Estimation for Mobile Positioning Applications. Thesis No. 1786, 2017.

K. Radnosrati: On Timing-Based Localization in Cellular Radio Networks. Thesis No. 1808, 2018.

G. Lindmark: Methods and Algorithms for Control Input Placement in Complex Networks. Thesis No. 1814, 2018.

M. Lindfors: Frequency Tracking for Speed Estimation. Thesis No. 1815, 2018.

D. Ho: Some results on closed-loop identification of quadcopters. Thesis No. 1826, 2018.

O. Ljungqvist: On motion planning and control for truck and trailer systems. Thesis No. 1832, 2019.

P. Boström-Rost: On Informative Path Planning for Tracking and Surveillance. Thesis No. 1838, 2019.

K. Bergman: On Motion Planning Using Numerical Optimal Control. Thesis No. 1843, 2019.

M. Klingspor: Low-rank optimization in system identification. Thesis No. 1855, 2019.

A. Bergström: Timing-Based Localization using Multipath Information. Thesis No. 1867, 2019.

F. Ljungberg: Estimation of Nonlinear Greybox Models for Marine Applications. Thesis No. 1880, 2020.

E. Hedberg: Control, Models and Industrial Manipulators. Thesis No. 1894, 2020.

R. Forsling: Decentralized Estimation Using Conservative Information Extraction. Thesis No. 1897, 2020. 
D. Arnström: On Complexity Certification of Active-Set QP Methods with Applications to Linear MPC. Thesis No. 1901, 2021.

M. Malmström: Uncertainties in Neural Networks: A System Identification Approach. Thesis No. 1902, 2021.

K. Nielsen: Robust LIDAR-Based Localization in Underground Mines. Thesis No. 1906, 2021.

H. Haghshenas: Time-Optimal Cooperative Path Tracking for Multi-Robot Systems. Thesis No. 1915, 2021. 


\section{FACULTY OF SCIENCE AND ENGINEERING}

Linköping Studies in Science and Technology, Licentiate Thesis No. 1917 Department of Electrical Engineering

Linköping University

SE-581 83 Linköping, Sweden

www.liu.se 